\title{
A year long comparison of GPS TEC and global ionosphere-thermosphere models
}

\author{
N. J. Perlongo, ${ }^{1}$ A. J. Ridley, ${ }^{1}$ I. Cnossen, ${ }^{2}$ C. Wu, ${ }^{1}$
}

Corresponding author: Nick Perlongo, Climate and Space Sciences and Engineering, University of Michigan, Ann Arbor, Michigan, USA. (nperlong@umich.edu)

${ }^{1}$ Climate and Space Sciences and

Engineering, University of Michigan, Ann

Arbor, Michigan, USA.

${ }^{2}$ British Antarctic Survey, Cambridge, UK

This is the author manuscript accepted for publication and has undergone full peer review but has not been through the copyediting, typesetting, pagination and proofreading process, which may lead to differences between this version and the Version of Record. Please cite this article as doi: $10.1002 / 2017$ JA024411 
X - 2

PERLONGO ET AL.: I-T VALIDATION

3 Abstract.

${ }_{4}$ The prevalence of GPS total electron content (TEC) observations has pro-

${ }_{5} \quad$ vided an opportunity for extensive global ionosphere-thermosphere model

validation efforts. This study presents a year long data-model comparison

using the Global Ionosphere-Thermosphere Model (GITM) and the Thermosphere-

Ionosphere-Electrodynamics General Circulation Model (TIE-GCM). For the

entire year of 2010, each model was run and compared to GPS TEC obser-

vations. The results were binned according to season, latitude, local time, and magnetic local time. GITM was found to overestimate the TEC everywhere, except on the mid-latitude nightside, due to high $\mathrm{O} / \mathrm{N}_{2}$ ratios. TIE-

3 GCM produced much less TEC and had lower $\mathrm{O} / \mathrm{N}_{2}$ ratios and neutral wind speeds. Seasonal and regional biases in the models are discussed along with ideas for model improvements and further validation efforts. 


\section{Introduction}

\section{8}

19

20

21

(2)

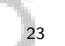

24

An important application of global ionosphere-thermosphere (IT) models is in understanding and predicting the total electron content (TEC) in the upper atmosphere. The advent of global TEC maps [Mannucci et al., 1998; Rideout and Coster, 2006] has afforded global modelers the ability to perform large scale data-model comparisons. Therefore, many studies have advocated the use of data assimilation to improve numerical models of the ionosphere [Hajj et al., 2004; Wang et al., 2004; Schunk and Nagy, 2004; Schunk et al., 2005; Scherliess et al., 2008; Chen et al., 2016; Chartier et al., 2016]. The purpose of this study is to investigate the performance of two models in comparison with GPS TEC data for the entire year of 2010. Results were compared for a variety of temporal and regional scales. In doing so, the capabilities of two different modeling approaches were quantified to highlight strengths and areas of bias in terms of TEC. This identification may then be used to investigate the sources of those biases in order to improve the models. Shim et al. [2012] performed a thorough analysis of a number of IT models in response to 9 different events. This paper expands on that study by focusing on just two models during an entire year of predominately quiet times.

Solar zenith angle dependent photoionization by solar extreme ultraviolet (EUV) radiation is the largest source of electrons in the dayside ionosphere [Hargreaves, 1992; Roble, 1995]. As such, there are variations in TEC by season [Wright, 1963; Tsurutani, 2004; Mannucci, 2005; Mendillo et al., 2005; Adimula et al., 2016], latitude [Liu et al., 2009a], local time [Scherliess et al., 2008], and the solar cycle and rotation period [Fejer et al., 1979; Forbes et al., 2000; Liu et al., 2009b]. Energetic particles from the solar wind and 

described in Section 2.

\section{Model and Data Description}



${ }_{71}$ of 30 minutes.

72 height.

species. Both models use a steady-state approximation for the ion momentum equation.

GITM uses a fixed altitude grid from $100 \mathrm{~km}$ to $600 \mathrm{~km}$ that allows for nonhydrostatic solutions to develop in the vertical momentum equation, while TIE-GCM has a vertical grid with pressure surfaces extending from about $97 \mathrm{~km}$ to $500-800 \mathrm{~km}$ depending on solar activity. The major neutral species in the TIE-GCM are $\mathrm{N}_{2}, \mathrm{O}_{2}$ and $\mathrm{O}$. The advected species in GITM are $\mathrm{N}_{2}, \mathrm{O}_{2}, \mathrm{O}, \mathrm{N}$, and NO. Both TIE-GCM and GITM advect $\mathrm{O}^{+}$and no other ions. TIE-GCM assumes steady-state electron density chemistry. In GITM, electron precipitation was provided by Fuller-Rowell and Evans [1987] and electric potentials were specified by Weimer [2005], driven by the upstream solar wind conditions observed from the ACE spacecraft [McComas et al., 1998; Smith et al., 1998]. TIE-GCM also used the Weimer model for the electric potentials, but used the Emery et al. [2008] precipitation model. TIE-GCM and GITM were run for the entire year of 2010 with an output cadence

The temperature and density of the thermosphere at the lower boundary of GITM (95$100 \mathrm{~km}$ ) was specified by the Mass Spectrometer and Incoherent Scatter (MSIS) model [Hedin, 1983, 1987, 1991]. As such, seasonal variations, diurnal and semi-diurnal migrating tides were empirically included in GITM's lower boundary. The horizontal wind patterns at the boundary were specified by the Horizontal Wind Model [Drob et al., 2008]. The Flare Irradiance Spectral Model (FISM) [Chamberlin et al., 2007] defined the solar extreme ultraviolet (EUV) flux. GITM was run with a resolution of $1.0^{\circ}$ latitude by $4.0^{\circ}$ longitude with a stretched altitude grid, resolving the vertical scales to approximately $1 / 3$ of a scale 
The TIE-GCM simulation had a resolution of $2.5^{\circ}$ latitude by $2.5^{\circ}$ longitude with 4 grid points per scale height. Daily and 81 day averaged $F_{10.7}$ were used to specify the solar EUV flux in accordance with the EUVAC model [Richards et al., 1994]. Since photoionization is a primary source of TEC, the difference in EUV flux model between GITM and TIE-GCM could be important. Peterson et al. [2009] showed that the EUVAC model prescribes a slightly higher solar irradiance power than the data on which the FISM model was based. It is therefore expected that TEC from photoionization will be larger in TIE-GCM. The difference between the two models is much greater during solar flares [Strickland et al., 2007], but this should not have affected the primarily quiet time results shown here.

The neutral temperature at the lower boundary of TIE-GCM was fixed at 181K, with a constant density. Both migrating and non-migrating tides were included in TIE-GCM through the specification of the altitude of the bottom pressure level as specified by the Global Scale Wave Model (GSWM) [Hagan and Forbes, 2002, 2003]. Since the tides are partly a result of solar EUV forcing, seasonal and local time variations exist within the GSWM. Some of the differences in results between the two models throughout the day and/or year may therefore be attributed to the different lower boundary conditions. Since each model is dependent on its inputs and drivers [e.g. Liuzzo et al., 2015], the results in this paper represent what occurred during typical model runs.

Uncertainties in internal model parameters also create differences between the models. These include the photoelectron heating efficiency, as well as eddy diffusion and thermal conductivity coefficients. The photoelectron heating efficiency defines what percentage of photoelectrons deposit energy into the thermosphere, which affects the temperature and the subsequent height of the thermosphere leading to varied recombination rates. An im- 
proved description of the photoelectron heating efficiency was developed by Burrell et al. [2015] that led to improved thermospheric neutral density data-model comparisons. However, thermal conductivity coefficients were found to have the largest impact on thermospheric composition compared to other uncertainties within the GITM model [Pawlowski and Ridley, 2009]. Eddy diffusion coefficients are known to have seasonal dependencies [Garcia and Solomon, 1985] that influence thermospheric neutral density and composition [Qian et al., 2009; Pilinski and Crowley, 2015]. Unlike TIE-GCM, the GITM model does not currently include a varied description of the eddy diffusion coefficient.

Model results were compared to ground-based global positioning system (GPS) receiver data provided by the Madrigal database at MIT Haystack Observatory [Rideout and Coster, 2006]. A map of the observational coverage separated into magnetic latitude regions is shown in Figure 1. The absolute accuracy of the slant-to-vertical derived TEC provided by GPS measurements is on the order 1-3 TECU [Mannucci et al., 1998; Tsurutani, 2004], where $1 \mathrm{TECU}=10^{16}$ electrons $\mathrm{m}^{-2}$. In each model comparison, the total electron content was calculated by integrating the electron density over the full altitude range. Corresponding values were then interpolated to the times and locations of the GPS observations. Since nearly all of the results represent solar quiet conditions, spurious interpolation results from sharp TEC gradients were assumed to be unimportant. The small contribution of electrons to the TEC in the region above the model boundaries were ignored. Yizengaw et al. [2008] investigated the plasmaspheric contribution to TEC using global GPS TEC data and JASON-1 TEC data. They found that the contribution varies with latitudes and local times with minimum of $10 \%$ during daytime and maximum of $60 \%$ at nighttime. Mazzella [2012] and Mazzella Jr. et al. [2017] analyzed a chain of 


\section{Results}

where $y_{i}$ is the measured value and $y_{i}^{*}$ is the model value. The model performs best when nRMSE is near 0 . If the nRMSE is larger than 1 , the data and the model have large differences, opposite trends, or both.

A map of the observational coverage separated into magnetic latitude regions is shown in Figure 1. Most longitudes are represented in the results due to the daily averaging

$$
n R M S E=\sqrt{\frac{\sum_{i=1}^{n}\left(y_{i}-y_{i}^{*}\right)^{2}}{\sum_{i=1}^{n}\left(y_{i}^{2}\right)}}
$$


of the TEC in our analysis. However, note that the coverage of the GPS TEC data is greater in the mid-latitudes and equatorial regions than the polar regions, especially in the southern hemisphere.

Plots C-G in Figure 2 show the GITM results in blue, TIE-GCM in red, and GPS observations in black for the entire year of 2010. Plots A and B show the $F_{10.7}$ and Dst indices for reference. All of the values in this figure are daily averages. The GITM and TIE-GCM results were averaged over all longitudes for each $30^{\circ}$ latitude bin shown in plots $\mathrm{C}-\mathrm{G}$, with the exception of the equatorial bin in plot E, which extends from $-30^{\circ}$ to $+30^{\circ}$. The first day of each month in the GITM simulations was omitted from the analysis to remove numerical effects introduced by restarting the simulation.

The $F_{10.7}$ values in plot A exhibit the characteristic 27-day rotation of the sun, but this period is not reflected in either the observations or the models. While $F_{10.7}$ has been shown to be a very good proxy for EUV flux on long time scales [Wintoft, 2011], a variation of $15 \mathrm{~W} / \mathrm{m}^{2} / \mathrm{Hz}$ between solar rotations was not enough to drive changes in average daily TEC values.

2010 was a relatively quiet year in terms of solar activity. The average daily Dst dropped below -40 nT only 5 times. Some of the larger spikes in the northern hemisphere GITM TEC correspond with these days, but not in the GPS measurements. Meanwhile, TIE-GCM had smaller increases in TEC in the southern mid-latitudes, which did agree with observations. GITM over-responded to geomagnetic storms in terms of TEC in the northern hemisphere, but not the southern.

TIE-GCM consistently under-predicted the GPS TEC at all latitudes and seasons, except for the polar winters. This is contrasted with an under-prediction by GITM during 
these times as is evident in December and January of plot C, which corresponds to latitudes above $60^{\circ}$. Here, the mean for TIE-GCM was 1.09 TECU above observations, but GITM was below by 1.14 TECU. For the months of May through July, below $60^{\circ}$ in the southern hemisphere winter, plot G shows that GITM's mean was 1.29 TECU lower than observations, while TIE-GCM was only 0.64 TECU higher. Contributing factors to these results include differences between the models in the EUV flux model, chemistry, upper boundary conditions, and neutral winds. The seasonal biases of each model are further investigated in the following sections.

The GITM TEC increased at all latitudes during the month of September, especially in the southern hemisphere. While this does correspond to an increase in F10.7, the same could be said about other months such as July where the GITM TEC stayed relatively constant at all latitudes. A similar, but less pronounced increase occurs in GITM during March, suggesting that this feature may be related to equinox conditions. This has been reproduced before in a version of TIE-GCM that included lower atmosphere dynamics [Mendillo et al., 2002] and was postulated to be related to neutral winds instead of composition changes in the thermosphere.

At all latitudes, there was more TEC near equinoxes than solstices in both the GITM and GPS observations. This was also true of TIE-GCM in the equatorial region, but still to smaller extent. These semiannual variations in low and mid-latitudes have been observed before and are related to thermospheric temperature and density, as well as the peak F2-layer height and electron density, $h \mathrm{mF} 2$ and $N \mathrm{mF} 2$, all of which peak near equinox [Rishbeth and Mendillo, 2001; Rishbeth, 2004]. The ability of GITM to capture this variation is possibly related to the use of MSIS-E90 [Hedin, 1987] for the lower 
boundary condition of the thermosphere. Hedin [1987] reported that the model has a minimum in atomic oxygen and molecular nitrogen in July, and a maximum in October at equatorial latitudes. Furthermore, the semiannual variation in MSIS is stronger in the southern hemisphere for oxygen, but stronger in the northern hemisphere for molecular nitrogen. Since oxygen is the main constituent of the thermosphere, photoionization of more oxygen should lead to more TEC in the southern hemisphere, which is what happened in GITM. Additionally, a stronger semiannual variation of $N_{2}$ in the northern hemisphere will decrease the $O / N_{2}$ ratio compared to the southern hemisphere, which will dampen the variation there. This is another characteristic seen in plots $\mathrm{C}$ and $\mathrm{G}$ of Figure 2 .

The results from Figure 2 are quantified in Table 1 using the nRMSE and PE metrics. Each metric is shown by geographic latitude, as well as for the entire globe in the final row. nRMSE was used to account for the differences in TEC magnitude between each latitude bin. While GITM was best in the equatorial region, it performed much better in the northern hemisphere with nRMSE's of 0.23 and 0.21 for northern polar and midlatitude regions. In the southern hemisphere, the nRMSE was 0.45 and 1.88 , respectively. This suggests that the model parameters in GITM may be over-fitted to the northern hemisphere. TIE-GCM also performed significantly worse in the southern mid-latitude region with an nRMSE of 3.59. TIE-GCM's error was 10x smaller in all other regions, performing better than GITM in the southern polar hemisphere, but worse in the northern hemisphere.

The PE for both models was negative at all latitude bins, except for GITM in the equatorial region. These are startling results because they indicate that, even though 


\section{(1)}

230

231

232

233

234 235 236

each model produced TEC with an RMSE of less than a few TECU, simply taking the mean of the observations would provide a better prediction of the globally averaged TEC during quiet times than either model in most cases. It should be noted that the PE for TIE-GCM, GITM, and other models was found to be worse during quiet times than during storms, presumably because an increase in the variance of observations decreases the PE [Shim et al., 2012]. Additionally, both models had a significantly worse PE in the northern mid-latitudes, approximately 3 times worse than any other latitude region. Perhaps this is expected, since physics from both the polar and equatorial regions are important here. This trend was not true in the southern mid-latitudes and will be investigated further in

Section 3.2

In the polar regions, coupling with the magnetosphere and solar wind dominates the movement of both the plasma and the neutrals in the upper atmosphere. As such, it makes sense to investigate each model's TEC results also in terms of magnetic local time (MLT). Additionally, viewing the TEC in magnetic coordinates ensures the equatorial anomaly stays within the equatorial latitude bin.

\subsection{MLT and Seasonal Dependence}

Figure 3 shows the TEC variation in MLT averaged over the different solstice and equinox months. These data were also averaged over magnetic latitude, such that this represents a global average of the TEC. The RMSE error is displayed in the bottom left corner of each plot. In all cases, TIE-GCM under predicted the observations, with RMSE's ranging from 2.1 TECU in December, to 4.2 TECU in September. GITM's results were much more varied. During the solstice months, GITM also under predicted the TEC, except in the dawn sector. During the equinox months, GITM consistently over predicted 
the TEC by up to 4 TECU on the dayside. The RMSE was the same for both equinox months at 3.1 TECU.

The June and December plots in Figure 3 reveal how much hemispheric asymmetry affects globally averaged TEC. If the rate plasma production was solely determined by insolation, these plots would have been very similar. However, there was a flattening of the post noon TEC peak in both the models and the observations in June, the northern hemisphere summer. Furthermore, the maximum of this peak was 1.5 TECU lower than in December in the GPS observations, 2.7 TECU for TIE-GCM, and 2.3 TECU for GITM. This phenomenon has been widely observed and is known as the $\mathrm{F}_{2}$ layer annual asymmetry. It has been attributed to a combination of neutral composition changes [Mendillo et al., 2005], influence of the lower atmosphere [Rishbeth, 2006], and the separation of the geographic and geomagnetic axes combined with the change in distance from the sun [Zeng and Horwitz, 2008]. The difference between hemispheres is likely subdued since the largest contributor of TEC is the equatorial region. To investigate this further, Figures 4, 5 and 6 show the same parameters split into latitudinal regions. Figure 4 represents all magnetic latitudes above $30^{\circ}$ in the northern hemisphere, such that the midlatitudes and polar regions from Figure 2 are merged. Figure 5 is the same except for in the southern hemisphere and Figure 6 is the equatorial region, from $-30^{\circ}$ to $30^{\circ}$ latitude.

Comparing Figures 4 and 5, a few notable differences arise both from model to model, and in the observations themselves. Starting with the observations during the solstices in the top row, the southern hemisphere TEC maximum varied from 12.5 TECU in December to 6 TECU in June, but stayed relatively constant between solstices at 8-9 TECU in the northern hemisphere. TIE-GCM performed very well in both winter hemispheres 
$\mathrm{X}-14$

PERLONGO ET AL.: I-T VALIDATION

with an RMSE of less than 1 TECU in both cases. GITM's RMSE ranged from 2.0 TECU to 2.6 TECU in the winter hemisphere, performing much better on the dayside than the nightside. In fact, GITM had almost no TEC on the nightside in the winter hemisphere. This is contrasted with TIE-GCM which had 3.5 TECU on the nightside during the summer and 3 TECU during the winter. The lack of nightside TEC in GITM is because the model does not include plasmaspheric drainage back to the ionosphere during the night time [Lunt et al., 1999; Yizengaw et al., 2008], allowing the TEC in GITM to decrease to almost zero. TIE-GCM specifies a nighttime and daytime flux from the plasmasphere that varies by latitude and solar zenith angle [Richmond, 1992], however it uses a fixed magnitude. The observations during both summer hemispheres indicated that TEC persists longer after dusk in the northern hemisphere. While both models did produce an elongated TEC peak, they began decreasing around 16 MLT, compared to the observed 19 MLT.

Figure 6 shows the results for the equatorial region. At the June and December GPS TEC peak, GITM overestimated the TEC by 2-5 TECU and TIE-GCM underestimated it by 4-7 TECU. The TIE-GCM peak was between 12 MLT to 15 MLT similar to the polar regions. Also during the solstices, GITM had a TEC peak on the dawnside near 9 MLT. To elucidate this and the other features described in this section, detailed contour plots are shown in Figures 8, 9, and 10.

The above TEC comparisons suffer from a methodological flaw in the sense that GPS measures the electron content integrated from the ground to the satellite altitude at about $20,000 \mathrm{~km}$, whereas the models extend only to roughly $600 \mathrm{~km}$. Furthermore, the altitude of the upper boundary of TIE-GCM varies with pressure so the upper bound of the TEC 
integration is not equal between the two models at all times. While the majority of ionospheric content lies below the model boundary [Schunk and Nagy, 2004], it is possible that TEC contributions between the upper boundary of the models and the height of the GPS satellites is significant enough to influence conclusions drawn from the TEC comparisons. It is important to consider how much bias is introduced into the results presented here resulting from the underestimation due to the differences in the altitude of integration.

To investigate this, the models were also compared to ionosonde NmF2 data, compliments of the Lowell GIRO Data Center (LGDC), at 4 different geographical locations in Figure 7. The geographic and magnetic latitudes of these locations, as well as the data coverage that was available for March and June are shown in Table 2. The locations were chosen to optimize data availability and latitudinal dispersion. An ionosonde was found for the northern polar (Nord), mid-latitude (Beijing), and equatorial (Sanya) regions, as well as the southern hemisphere mid-latitudes (Grahamstown). To get the trend of the NmF2 in March and June, 2010, data of each hour were averaged over the entire month at each location. Missing data was neglected in the averaging.

Figure 7 shows results for each location in the columns, with March in the top row and June in the bottom row. Since each subplot is analogous to a subplot from the previous 3 Figures, the corresponding plot is indicated in the upper left-hand corner for each subplot. The NmF2 results mirror those from the TEC comparison in Figures 2-5, confirming the conclusion that TIE-GCM generally under-predicted electron densities during the daytime, whereas GITM was either close or an over-estimate of the observations. A good example of this is was in June at Grahamstown in the southern mid-latitudes, where 


\subsection{TEC Maps}

325 
In each figure, the northern and southern hemispheres are shown pole-ward of $60^{\circ}$ geomagnetic latitude in the left and right polar plots, respectively. TEC for the entire planet versus local time is shown in the rectangle plot, separated by the same latitude bins as Figure 2. These figures were averaged over the entire month of June to dampen the signal to noise ratio of the plots in addition to diurnal variations and the peak of each solstice. Since they are in local time coordinates, any longitudinal features were also erased which helps to compensate for the sparse data coverage over oceans. Viewing the entire month allowed patterns to emerge rather than possible transient structures that may have existed on the actual solstice. All of the results were taken at the vertical TEC locations and the averaging and plots were made exactly the same way with the observational data and models.

The structure of the GPS TEC in the polar region of the northern hemisphere in Figure 8 was different than expected considering just photoionization alone, since one might expect that the electron density would decrease from the dayside to the nightside in accordance with the solar zenith angle. The TEC wrapped around the globe extensively, creating a TEC hole between $75^{\circ}$ and $85^{\circ}$ from $23-02$ LT. The TEC hole may have been created by the $\mathbf{E} \times \mathbf{B}$ ion drift transporting plasma downwards on the nightside into a region of higher neutral density where charge exchange and recombination rates are faster. Deng [2006] suggested that ions are advected upwards on the dayside into the F-region ionosphere, transported towards the nightside, and advected downwards. This happens because on a non-vertical magnetic field line, the $\mathbf{E} \times \mathbf{B}$ drift can have a component in the vertical direction, which tends to be downwards on the nightside, resulting in a hole, and upward on the dayside, resulting in a tongue of ionization. 
The TEC in the northern polar latitudes in the GITM simulation was stratified across the polar cap predominately in accordance with solar zenith angle dependent photoionozation. The upper left plot in Figure 9 shows that the TEC steadily decreased from about 10 TECU at $12 \mathrm{LT}$ to 4 TECU at $00 \mathrm{LT}$ at $60^{\circ}$. The TEC hole in the polar cap was not reproduced. The polar winter hemisphere was similarly stratified on the dayside, with elevated TEC in the auroral region.

The GITM dayside equatorial TEC maximum did not spread into the midlatitudes nearly as much as the GPS measurements. For example, the GITM TEC dropped to 50\% of its peak value by $28^{\circ}$ latitude at $12 \mathrm{LT}$. This is contrasted with nearly $40^{\circ}$ in the GPS TEC. Furthermore, there was a deep TEC minimum on the nightside at mid-latitudes which likely corresponded to the lack of plasmaspheric refilling in the model. This also occurred in the southern hemisphere mid and polar latitudes. However, many electrons persisted in the nightside ionosphere in GITM in the equatorial region. The equatorial anomaly in GITM is exceedingly efficient at lifting plasma in this region, possibly resulting in the nightside enhancement as well as the faster decline in TEC towards mid-latitudes. This occurs because as plasma is lifted to higher altitudes, the neutral density is less and recombination happens more slowly, allowing electrons to persist longer.

TEC in the TIE-GCM simulation had a different structure than in either GITM or the GPS observations. Shown in Figure 10 for the same time period, the TEC in both polar regions was nearly uniform between 2.67 and 4.00 TECU. While the plasmaspheric drainage sustained the polar winter TEC, a TEC decrease in the polar cap did not evolve. An equatorial anomaly was not as present in the TIE-GCM results, but the single TEC maximum in the equatorial region was positioned closer to the observations between 12 
377

and $17 \mathrm{LT}$ at $5^{\circ}$ latitude in the northern hemisphere, whereas GITM had a broad TEC maximum from dawn to dusk. Except for the southern polar region, the nightside TEC in the TIE-GCM simulation was also smaller than in the observations, but to a lesser extent than in GITM.

Both models reproduced the structure of the GPS TEC observations relatively well during March. Figures 11, 12, and 13 show contour plots of the TEC averaged over the month for the observations, GITM, and TIE-GCM respectively. Note that compared to the June figures, the maximum scales are increased to 50 TECU in the rectangle plot and 25 TECU in the polar plots.

The GPS observations had a couple distinguishing features. The first is that the most TEC resided between 12-18 LT from $-8^{\circ}$ to $-15^{\circ}$ latitude. In September, this peak occurred in the northern hemisphere (not shown). TIE-GCM matched the local times of the maximum, but peaked closer to the equator, with narrow TEC enhancements from the equatorial anomaly. GITM peaked much later in the day, from 14-17 LT, as well as in the northern hemisphere near $10^{\circ}$ latitude.

The second feature is that there was an extension of the equatorial TEC into the dusk side, extending from 15-00 LT. The observations were characterized by TEC extending from $17-20 \mathrm{LT}$ as well as at $0^{\circ}$ and $-9^{\circ}$ that are most visible by the contour lines from $21-23$ LT. TIE-GCM captured this structure very well, but missed the smaller scale extensions. The opposite was true of the GITM results, where even more TEC extended towards the dusk side, especially in the southern hemisphere. 
Contour plots for the December and September months are not shown primarily because they were similar and/or lacked significant features. In December, the structure of the GITM and TIE-GCM simulations were very similar to June with the hemispheres reversed.

Thematic of the results was a tendency for GITM to overestimate the GPS TEC observations, and for TIE-GCM to underestimate them. There are four main factors that may have contributed to this bias in either model; 1) EUV flux model, 2) boundary conditions, 3) neutral winds, and 4) chemistry.

As discussed in Section 2, the TIE-GCM simulations used the EUVAC model, which has been shown to produce a higher solar irradiance power than the FISM model that GITM used [Peterson et al., 2009]. Since this is opposite of what occurred in the simulations, it is unlikely that the EUV flux model was as important to driving the differences in TEC as the other three factors mentioned above. In the nightside mid-latitudes of GITM the TEC is depleted very quickly with no refilling from the plasmasphere. This is an obvious feature in GITM that should be corrected. Despite this regional lack of TEC, GITM still overpredicted the TEC as a whole during most of the year considering all latitudes, and even more-so during the equinoxes. More regional differences may be attributed to lower boundary conditions, especially concerning atmospheric tide specifications in each model. Since tidal features are often bound to specific regions and altitudes, it is expected that the primary reasons for the TEC differences between TIE-GCM and GITM were related to chemistry and neutral winds.

Figure 14 shows $\mathrm{O} / \mathrm{N}_{2}$ ratios for both models at $12 \mathrm{UT}$ on March equinox. The ratios were calculated by integrating the $\mathrm{O}$ and $\mathrm{N}_{2}$ densities from the top of the model down to the altitude where the $\mathrm{N}_{2}$ density was equal to $2 \times 10^{21} \mathrm{~m}^{-3}$. The GITM ratios were much 


\section{Summary and Conclusions}

This study presented a year long analysis of GPS TEC observations compared with model results from TIE-GCM and GITM during 2010. A number of seasonal and local time biases were revealed in the models in addition to some phenomena that neither model captured. The main findings are described below.

- For the simulation settings described in Section 2, TIE-GCM under-predicted the TEC during all seasons and latitudes except for polar winters whereas GITM primarily over-predicted the TEC. This resulted primarily from chemistry and neutral winds. GITM had much higher $\mathrm{O} / \mathrm{N}_{2}$ ratios and stronger neutral winds than TIE-GCM.

- GITM performed best in the northern hemisphere with decreasing accuracy towards the south pole. Since model development is often focused on the northern hemisphere due to data availability, this result suggests that GITM may be over-fitted to the northern hemisphere. The smaller sample size of observations in the southern hemisphere or larger offset of the geomagnetic pole may have also contributed to this bias. TIE-GCM performed best in the polar regions with decreasing accuracy towards the equator primarily due to less TEC near the subsolar point combined with a weaker equatorial anomaly.

- GITM had almost no TEC on the mid-latitude nightside since the model does not include plasmaspheric refilling processes. The equatorial anomaly in GITM was very strong and contributed to TEC persisting on the duskside after being lifted to high altitudes. The equatorial anomaly was very weak or not present in TIE-GCM, but the TEC values near midnight were consistent with observations.

Future research projects should take these biases into consideration and use the model that best represents the time or region of interest. This study focused primarily on quiet 


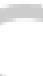

. 


\section{References}

Adimula, I. A., O. A. Oladipo, and S. J. Adebiyi (2016), Latitudinal and Seasonal Investigations of Storm-Time TEC Variation, Pure and Applied Geophysics, 173(7), 25212533, doi:10.1007/s00024-016-1291-2.

Afraimovich, E., E. Astafyeva, V. Demyanov, and I. Gamayunov (2009), Mid-latitude amplitude scintillation of GPS signals and GPS performance slips, Advances in Space Research, 43(6), 964-972, doi:10.1016/j.asr.2008.09.015.

Bramley, E., and M. Young (1968), Winds and electromagnetic drifts in the equatorial F2-region, Journal of Atmospheric and Terrestrial Physics, 30(1), 99-111, doi: 10.1016/0021-9169(68)90044-5.

Buonsanto, M. (1999), Ionospheric Storms A Review, Space Science Reviews, 88(3/4), 563-601, doi:10.1023/A:1005107532631.

Burrell, A., A. Goel, A. Ridley, and D. Bernstein (2015), Correction of the photoelectron heating efficiency within the global ionospherethermosphere model using Retrospective Cost Model Refinement, Journal of Atmospheric and Solar-Terrestrial Physics, 124, 30-38, doi:10.1016/j.jastp.2015.01.004.

Burrell, A. G., R. A. Heelis, and R. A. Stoneback (2012), Equatorial longitude and local time variations of topside magnetic field-aligned ion drifts at solar minimum, Journal of Geophysical Research, 117(A4), A04,304, doi:10.1029/2011JA017264.

Burrell, A. G., R. A. Heelis, and A. Ridley (2013), Daytime altitude variations of the equatorial, topside magnetic field-aligned ion transport at solar minimum, Journal of Geophysical Research: Space Physics, 118(6), 3568-3575, doi:10.1002/jgra.50284. 
Chamberlin, P. C., T. N. Woods, and F. G. Eparvier (2007), Flare Irradiance Spectral Model (FISM): Daily component algorithms and results, Space Weather, 5(7), n/a-n/a, doi:10.1029/2007SW000316.

Chartier, A. T., T. Matsuo, J. L. Anderson, N. Collins, T. J. Hoar, G. Lu, C. N. Mitchell, A. J. Coster, L. J. Paxton, and G. S. Bust (2016), Ionospheric data assimilation and forecasting during storms, Journal of Geophysical Research: Space Physics, 121(1), 764-778, doi:10.1002/2014JA020799.

Chen, C. H., C. H. Lin, T. Matsuo, W. H. Chen, I. T. Lee, J. Y. Liu, J. T. Lin, and C. T. Hsu (2016), Ionospheric data assimilation with thermosphere-ionosphereelectrodynamics general circulation model and GPS-TEC during geomagnetic storm conditions, Journal of Geophysical Research: Space Physics, 121(6), 5708-5722, doi: 10.1002/2015JA021787.

Deng, . (2006), Examining the high latitude thermosphere and ionosphere using a global model, ProQuest Dissertations And Theses; Thesis (Ph.D.)-University of Michigan.

Drob, D. P., J. T. Emmert, G. Crowley, J. M. Picone, G. G. Shepherd, W. Skinner, P. Hays, R. J. Niciejewski, M. Larsen, C. Y. She, J. W. Meriwether, G. Hernandez, M. J. Jarvis, D. P. Sipler, C. A. Tepley, M. S. O'Brien, J. R. Bowman, Q. Wu, Y. Murayama, S. Kawamura, I. M. Reid, and R. A. Vincent (2008), An empirical model of the Earth's horizontal wind fields: HWM07, Journal of Geophysical Research: Space Physics, 113(A12), n/a-n/a, doi:10.1029/2008JA013668.

Emery, B. A., V. Coumans, D. S. Evans, G. A. Germany, M. S. Greer, E. Holeman, K. Kadinsky-Cade, F. J. Rich, and W. Xu (2008), Seasonal, Kp, solar wind, and solar flux variations in long-term single-pass satellite estimates of electron and ion auroral 
hemispheric power, Journal of Geophysical Research: Space Physics, $113(\mathrm{~A} 6)$, n/a-n/a, doi:10.1029/2007JA012866.

Fejer, B., D. Farley, R. Woodman, and C. Calderon (1979), Dependence of equatorial $<\mathrm{i}>\mathrm{F}</ \mathrm{i}>$ region vertical drifts on season and solar cycle, Journal of Geophysical Research, 84(A10), 5792, doi:10.1029/JA084iA10p05792.

Forbes, J. M. (1996), Planetary Waves in the Thermosphere-Ionosphere System., Journal of geomagnetism and geoelectricity, 48(1), 91-98, doi:10.5636/jgg.48.91.

Forbes, J. M., S. E. Palo, and X. Zhang (2000), Variability of the ionosphere, Journal of Atmospheric and Solar-Terrestrial Physics, 62(8), 685-693, doi:10.1016/S13646826(00)00029-8.

Fuller-Rowell, T., M. Codrescu, C. Minter, and D. Strickland (2006), Application of thermospheric general circulation models for space weather operations, Advances in Space Research, 37(2), 401-408, doi:10.1016/j.asr.2005.12.020.

Fuller-Rowell, T. J., and D. S. Evans (1987), Height-integrated Pedersen and Hall conductivity patterns inferred from the TIROS-NOAA satellite data, Journal of Geophysical Research, 92(A7), 7606, doi:10.1029/JA092iA07p07606.

Förster, M., and I. Cnossen (2013), Upper atmosphere differences between northern and southern high latitudes: The role of magnetic field asymmetry, Journal of Geophysical Research: Space Physics, 118(9), 5951-5966, doi:10.1002/jgra.50554.

Garcia, R. R., and S. Solomon (1985), The effect of breaking gravity waves on the dynamics and chemical composition of the mesosphere and lower thermosphere, Journal of Geophysical Research, 90 (D2), 3850, doi:10.1029/JD090iD02p03850. 
Goncharenko, L. P., J. L. Chau, H.-L. Liu, and A. J. Coster (2010), Unexpected connections between the stratosphere and ionosphere, Geophysical Research Letters, 37(10), n/a-n/a, doi:10.1029/2010GL043125.

Hagan, M. E., and J. M. Forbes (2002), Migrating and nonmigrating diurnal tides in the middle and upper atmosphere excited by tropospheric latent heat release, Journal of Geophysical Research, 10(D24), 4754, doi:10.1029/2001JD001236.

Hagan, M. E., and J. M. Forbes (2003), Migrating and nonmigrating semidiurnal tides in the upper atmosphere excited by tropospheric latent heat release, Journal of Geophysical Research: Space Physics, 108(A2), doi:10.1029/2002JA009466.

Hajj, G. A., B. D. Wilson, C. Wang, X. Pi, and I. G. Rosen (2004), Data assimilation of ground GPS total electron content into a physics-based ionospheric model by use of the Kalman filter, Radio Science, 39(1), n/a-n/a, doi:10.1029/2002RS002859.

Hargreaves, J. K. (1992), The solarterrestrial environment, Cambridge University Press, Cambridge, doi:10.1017/CBO9780511628924.

Hedin, A. E. (1983), A Revised thermospheric model based on mass spectrometer and incoherent scatter data: MSIS-83, Journal of Geophysical Research, 88(A12), 10,170, doi:10.1029/JA088iA12p10170.

Hedin, A. E. (1987), MSIS-86 Thermospheric Model, Journal of Geophysical Research, 92(A5), 4649, doi:10.1029/JA092iA05p04649.

Hedin, A. E. (1991), Extension of the MSIS Thermosphere Model into the middle and lower atmosphere, Journal of Geophysical Research, 96(A2), 1159, doi: 10.1029/90JA02125. 
Hedin, A. E., and H. G. Mayr (1973), Magnetic control of the near equatorial neutral thermosphere, Journal of Geophysical Research, 78(10), 1688-1691, doi: 10.1029/JA078i010p01688.

Immel, T. J. (2005), Global storm time plasma redistribution imaged from the ground and space, Geophysical Research Letters, 32(3), L03,107, doi:10.1029/2004GL021120.

Immel, T. J., S. L. England, X. Zhang, J. M. Forbes, and R. DeMajistre (2009), Upward propagating tidal effects across the E- and F-regions of the ionosphere, Earth, Planets and Space, 61(4), 505-512, doi:10.1186/BF03353167.

Jakowski, N., V. Wilken, S. Schlueter, S. Stankov, and S. Heise (2005), Ionospheric space weather effects monitored by simultaneous ground and space based GNSS signals, Journal of Atmospheric and Solar-Terrestrial Physics, 67(12), 1074-1084, doi: 10.1016/j.jastp.2005.02.023.

Jones, K., and H. Rishbeth (1971), The origin of storm increases of mid-latitude F-layer electron concentration, Journal of Atmospheric and Terrestrial Physics, 33(3), 391-401, doi:10.1016/0021-9169(71)90144-9.

Liu, L., B. Zhao, W. Wan, B. Ning, M.-L. Zhang, and M. He (2009a), Seasonal variations of the ionospheric electron densities retrieved from Constellation Observing System for Meteorology, Ionosphere, and Climate mission radio occultation measurements, Journal of Geophysical Research: Space Physics, 114(A2), n/a-n/a, doi:10.1029/2008JA013819.

Liu, L., W. Wan, B. Ning, and M.-L. Zhang (2009b), Climatology of the mean total electron content derived from GPS global ionospheric maps, Journal of Geophysical Research: Space Physics, 114(A6), n/a-n/a, doi:10.1029/2009JA014244. 
Liuzzo, L. R., A. J. Ridley, N. J. Perlongo, E. J. Mitchell, M. Conde, D. L. Hampton, W. A. Bristow, and M. J. Nicolls (2015), High-latitude ionospheric drivers and their effects on wind patterns in the thermosphere, Journal of Geophysical Research: Space Physics, 120(1), 715-735, doi:10.1002/2014JA020553.

Lunt, N., L. Kersley, and G. J. Bailey (1999), The influence of the protonosphere on GPS observations: Model simulations, Radio Science, 34(3), 725-732, doi: 10.1029/1999RS900002.

Mannucci, A. J. (2005), Dayside global ionospheric response to the major interplanetary events of October 2930, 2003 Halloween Storms, Geophysical Research Letters, 32(12), L12S02, doi:10.1029/2004GL021467.

Mannucci, A. J., B. D. Wilson, D. N. Yuan, C. H. Ho, U. J. Lindqwister, and T. F. Runge (1998), A global mapping technique for GPS-derived ionospheric total electron content measurements, Radio Science, 33(3), 565-582, doi:10.1029/97RS02707.

Mazzella, A. J. (2012), Determinations of plasmasphere electron content from a latitudinal chain of GPS stations, Radio Science, 47(1), n/a-n/a, doi:10.1029/2011RS004769.

Mazzella Jr., A. J., J. B. Habarulema, and E. Yizengaw (2017), Determinations of ionosphere and plasmasphere electron content for an African chain of GPS stations, Annales Geophysicae, 35(3), 599-612, doi:10.5194/angeo-35-599-2017.

McComas, ., . Bame, . Barker, . Feldman, . Phillips, . Riley, and . Griffee (1998), Solar Wind Electron Proton Alpha Monitor (SWEPAM) for the Advanced Composition Explorer, Space Science Reviews, (1), 563-612, doi:10.1023/A:1005040232597.

Mendillo, M. (2006), Storms in the ionosphere: Patterns and processes for total electron content, Reviews of Geophysics, 44(4), RG4001, doi:10.1029/2005RG000193. 
Mendillo, M., H. Rishbeth, R. Roble, and J. Wroten (2002), Modelling F2-layer seasonal trends and day-to-day variability driven by coupling with the lower atmosphere, Journal of Atmospheric and Solar-Terrestrial Physics, 64(18), 1911-1931, doi:10.1016/S13646826(02)00193-1.

Mendillo, M., C.-L. Huang, X. Pi, H. Rishbeth, and R. Meier (2005), The global ionospheric asymmetry in total electron content, Journal of Atmospheric and SolarTerrestrial Physics, 67(15), 1377-1387, doi:10.1016/j.jastp.2005.06.021.

Muella, M. T. A. H., E. R. de Paula, P. R. Fagundes, J. A. Bittencourt, and Y. Sahai (2010), Thermospheric Meridional Wind Control on Equatorial Scintillations and the Role of the Evening F-Region Height Rise, EB Drift Velocities and F2-Peak Density Gradients, Surveys in Geophysics, 31(5), 509-530, doi:10.1007/s10712-010-9101-3.

Pawlowski, D. J., and A. J. Ridley (2009), Quantifying the effect of thermospheric parameterization in a global model, Journal of Atmospheric and Solar-Terrestrial Physics, 71(17), 2017-2026, doi:10.1016/j.jastp.2009.09.007.

Perlongo, N. J., and A. J. Ridley (2016), Universal time effect in the response of the thermosphere to electric field changes, Journal of Geophysical Research: Space Physics, 121(4), 3681-3698, doi:10.1002/2015JA021636.

Peterson, W. K., E. N. Stavros, P. G. Richards, P. C. Chamberlin, T. N. Woods, S. M. Bailey, and S. C. Solomon (2009), Photoelectrons as a tool to evaluate spectral variations in solar EUV irradiance over solar cycle timescales, Journal of Geophysical Research: Space Physics, 114(A10), n/a-n/a, doi:10.1029/2009JA014362.

Pi, X., A. J. Mannucci, U. J. Lindqwister, and C. M. Ho (1997), Monitoring of global ionospheric irregularities using the Worldwide GPS Network, Geophysical Research Letters, 
633

634

635

636

24(18), 2283-2286, doi:10.1029/97GL02273.

Pilinski, M. D., and G. Crowley (2015), Seasonal variability in global eddy diffusion and the effect on neutral density, Journal of Geophysical Research: Space Physics, 120(4), 3097-3117, doi:10.1002/2015JA021084.

Qian, L., S. C. Solomon, and T. J. Kane (2009), Seasonal variation of thermospheric density and composition, Journal of Geophysical Research: Space Physics, 114(A1), n/a-n/a, doi:10.1029/2008JA013643.

Qian, L., A. G. Burns, S. C. Solomon, and W. Wang (2013), Annual/semiannual variation of the ionosphere, Geophysical Research Letters, 40(10), 1928-1933, doi: $10.1002 / \operatorname{grl} .50448$.

Richards, P. G., J. A. Fennelly, and D. G. Torr (1994), EUVAC: A solar EUV Flux Model for aeronomic calculations, Journal of Geophysical Research, 99(A5), 8981, doi: 10.1029/94JA00518.

Richmond, A. (1992), Assimilative mapping of ionospheric electrodynamics, Advances in Space Research, 12(6), 59-68, doi:10.1016/0273-1177(92)90040-5.

Rideout, W., and A. Coster (2006), Automated GPS processing for global total electron content data, GPS Solutions, 10(3), 219-228, doi:10.1007/s10291-006-0029-5.

Ridley, A., Y. Deng, and G. Tóth (2006), The global ionospherethermosphere model, Journal of Atmospheric and Solar-Terrestrial Physics, 68(8), 839-864, doi: 10.1016/j.jastp.2006.01.008.

Rishbeth, H. (2004), Questions of the equatorial F2-layer and thermosphere, Journal of Atmospheric and Solar-Terrestrial Physics, 66(17), 1669-1674, doi: 10.1016/j.jastp.2004.07.008. 
656

Rishbeth, H. (2006), F-region links with the lower atmosphere?, Journal of Atmospheric and Solar-Terrestrial Physics, 68(3), 469-478, doi:10.1016/j.jastp.2005.03.017.

Rishbeth, H., and M. Mendillo (2001), Patterns of F2-layer variability, Journal of Atmospheric and Solar-Terrestrial Physics, 63(15), 1661-1680, doi:10.1016/S13646826(01)00036-0.

Rishbeth, H., and I. C. F. Müller-Wodarg (1999), Vertical circulation and thermospheric composition: a modelling study, Annales Geophysicae, 17(6), 794-805, doi: 10.1007/s00585-999-0794-x.

Rishbeth, H., T. Fuller-Rowell, and D. Rees (1987), Diffusive equilibrium and vertical motion in the thermosphere during a severe magnetic storm : A computational study, Planetary and Space Science, 35(9), 1157-1165, doi:10.1016/0032-0633(87)90022-5.

Rishbeth, ., . Ganguly, and . Walker (1978), Field-aligned and field-perpendicular velocities in the ionospheric F2-layer, Journal of Atmospheric and Terrestrial Physics, 40, $767-784$.

Roble, R. G. (1995), Energetics of the mesosphere and thermosphere, pp. 1-21, American Geophysical Union, doi:10.1029/GM087p0001.

Roble, R. G., E. C. Ridley, A. D. Richmond, and R. E. Dickinson (1988), A coupled thermosphere/ionosphere general circulation model, Geophysical Research Letters, 15(12), 1325-1328, doi:10.1029/GL015i012p01325.

Scherliess, L., D. C. Thompson, and R. W. Schunk (2008), Longitudinal variability of low-latitude total electron content: Tidal influences, Journal of Geophysical Research: Space Physics, 113(A1), n/a-n/a, doi:10.1029/2007JA012480. 
Tsurutani, B. T., O. P. Verkhoglyadova, A. J. Mannucci, G. S. Lakhina, G. Li, and G. P. Zank (2009), A brief review of solar flare effects on the ionosphere, Radio Science, 44(1), n/a-n/a, doi:10.1029/2008RS004029.

Vladimer, J. A., P. Jastrzebski, M. C. Lee, P. H. Doherty, D. T. Decker, and D. N. Anderson (1999), Longitude structure of ionospheric total electron content at low latitudes measured by the TOPEX/Poseidon satellite, Radio Science, 34(5), 1239-1260, doi:10.1029/1999RS900060.

Volland, H. (1995), Handbook of atmospheric electrodynamics, CRC Press.

Wang, C., G. Hajj, X. Pi, I. G. Rosen, and B. Wilson (2004), Development of the Global Assimilative Ionospheric Model, Radio Science, 39(1), n/a-n/a, doi: 10.1029/2002RS002854.

Weimer, D. R. (2005), Improved ionospheric electrodynamic models and application to calculating Joule heating rates, Journal of Geophysical Research, 110(A5), A05,306, doi:10.1029/2004JA010884.

Wintoft, P. (2011), The variability of solar EUV: A multiscale comparison between sunspot number, $10.7 \mathrm{~cm}$ flux, LASP MgII index, and SOHO/SEM EUV flux, Journal of Atmospheric and Solar-Terrestrial Physics, 73(13), 1708-1714, doi: 10.1016/j.jastp.2011.03.009.

Wright, J. W. (1963), The $<\mathrm{i}>\mathrm{F}</ \mathrm{i}>$-region seasonal anomaly, Journal of Geophysical Research, 68(14), 4379-4381, doi:10.1029/JZ068i014p04379.

Yizengaw, E., M. Moldwin, D. Galvan, B. Iijima, A. Komjathy, and A. Mannucci (2008), Global plasmaspheric TEC and its relative contribution to GPS TEC, Journal of Atmospheric and Solar-Terrestrial Physics, 70(11), 1541-1548, doi: 
10.1016/j.jastp.2008.04.022.

Zeng, W., and J. L. Horwitz (2008), Storm enhanced densities (SED) as possible sources for Cleft Ion Fountain dayside ionospheric outflows, Geophysical Research Letters, 35(4), L04,103, doi:10.1029/2007GL032511.

Zhu, J., and A. J. Ridley (2014), The effect of background conditions on the ionospheric response to solar flares, Journal of Geophysical Research: Space Physics, 119(6), 50605075, doi:10.1002/2014JA019887.

Acknowledgments. This research was supposed by NSF through grants AGS-1452097 and 1462362 and NASA grant NNX14AE04G. GPS TEC data used in this study was obtained from Millstone Hill/Haystack Observatory. This work was made possible by NASA HEC Pleiades allocation. We would also like to thank the International Space Science Institute (ISSI) for supporting this collaborative effort. Simulation results are available upon request. Ingrid Cnossen was sponsored by a fellowship of the Natural Environment Research Council, grant number NE/J018058/1. The August 2018 GITM source code and model input files used to run the simulations presented in this study and eventually the full 3D model output will be made available on University of Michigan's Deep Blue Data storage system (doi:10.7302/Z28K7788). The TIE-GCM input files and job files will also be included there. 
Table 1. Normalized root mean-square error (NRMSE) in TECU and prediction efficiency (PE) for GITM and TIE-GCM versus GPS TEC observations. The values are taken from daily averages for the entire year of 2010 .

\begin{tabular}{c|c|c|c|c} 
& \multicolumn{2}{|c|}{ GITM } & \multicolumn{2}{c}{ TIE-GCM } \\
\hline & NRMSE & PE & NRMSE & PE \\
\hline North Polar & 0.23 & -0.31 & 0.37 & -2.45 \\
\hline North Mid-Lats & 0.21 & -1.57 & 0.43 & -9.83 \\
\hline Equatorial & 0.13 & 0.42 & 0.37 & -3.34 \\
\hline South Mid-Lats & 1.88 & -0.19 & 3.59 & -3.32 \\
\hline South Polar & 0.45 & -0.45 & 0.39 & -0.07 \\
\hline \hline All & 0.58 & -0.42 & 1.03 & -3.80
\end{tabular}

Table 2. Geographic and magnetic coordinates at each location. Data coverage is also shown in the 3rd and 4th column for March and June of 2010.

\begin{tabular}{ccccc} 
& \multicolumn{2}{c}{ Coordinates } & \multicolumn{2}{c}{ Data Coverage (d) } \\
\hline & Geographic & Magnetic & March & June \\
\hline Nord, GL & $(81.4,342.5)$ & $(81.4,129.9)$ & 31 & 30 \\
\hline Beijing & $(42.8,-116.2)$ & $(33,-165.5)$ & 31 & 30 \\
\hline Sanya & $(18.3,109.4)$ & $(8.21,-178.3)$ & 31 & 30 \\
\hline Grahamstown & $(-33.3,26.5)$ & $(-34.1,92.1)$ & 29 & 25 \\
\hline
\end{tabular}




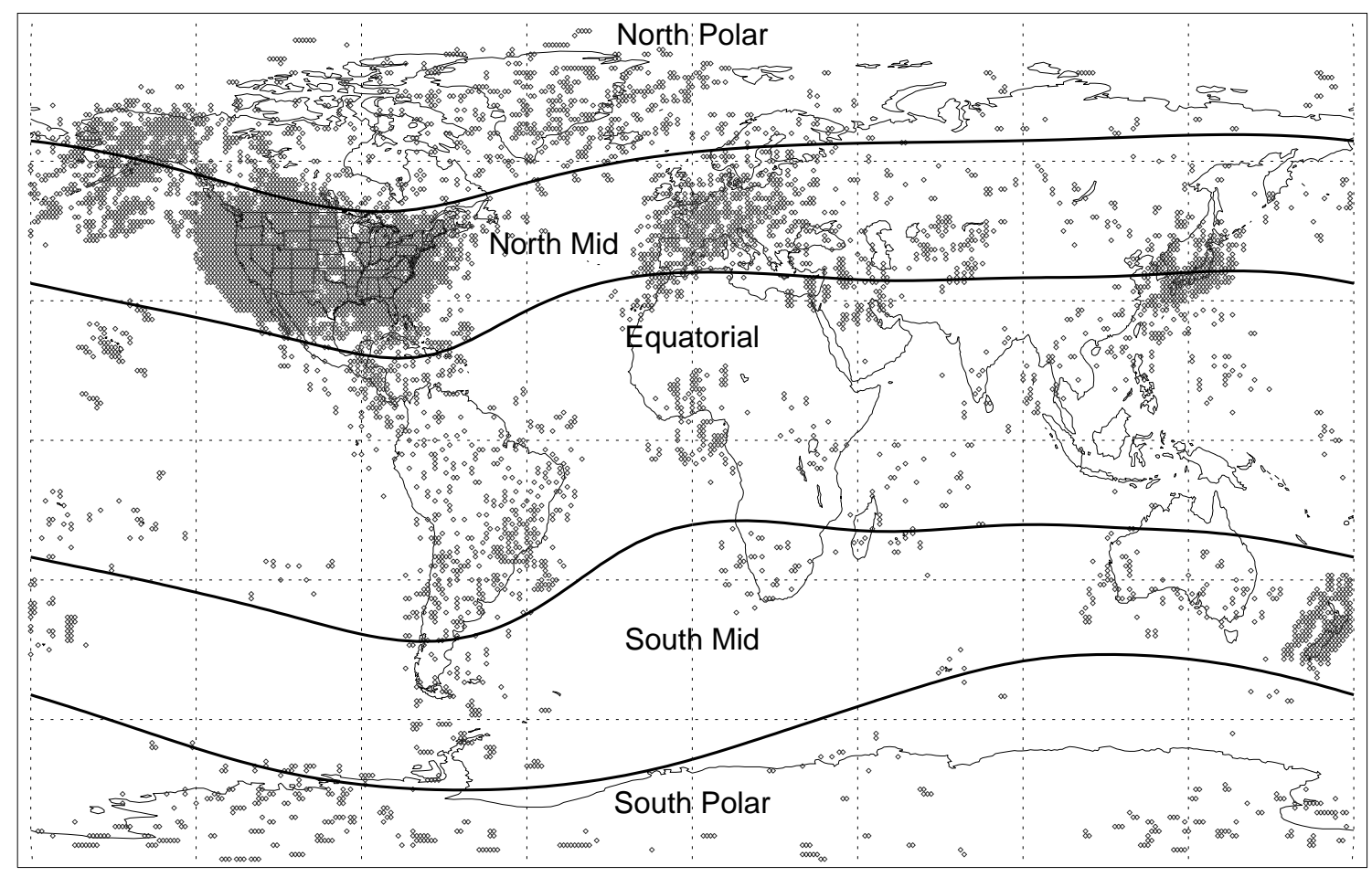

Figure 1. Locations of the GPS TEC observations in 2010. The geomagnetic latitudes corresponding $+/-30^{\circ}$ and $+/-60^{\circ}$ are shown as the solid black lines. 


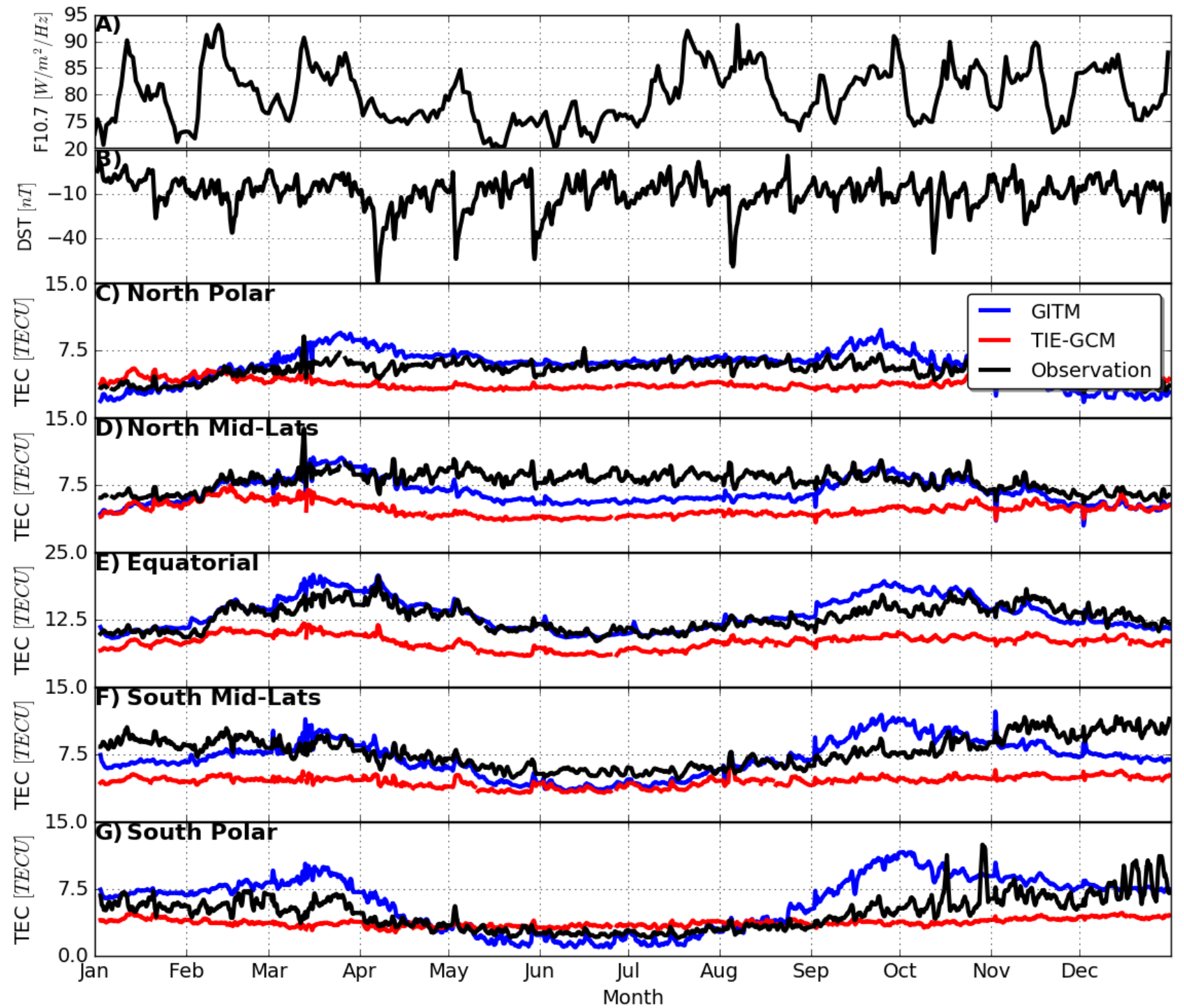

Figure 2. $\quad F_{10.7}$ and Dst in the first two rows followed by daily averages of the TEC in 5 different regions in plot

s C-G. GITM results are plotted in blue, TIE-GCM in red, and observations in black. Note that the scale in the equatorial region in plot E goes to 25 TECU instead of 15. Each plot represents a $30^{\circ}$ bin in geographic latitude. Plot $\mathrm{C}$ represents latitudes from $60^{\circ}$ to $90^{\circ}$, plot $\mathrm{D}$ from $30^{\circ}$ to $59^{\circ}$ to degrees, and so on.

This article is protected by copyright. All rights reserved. 


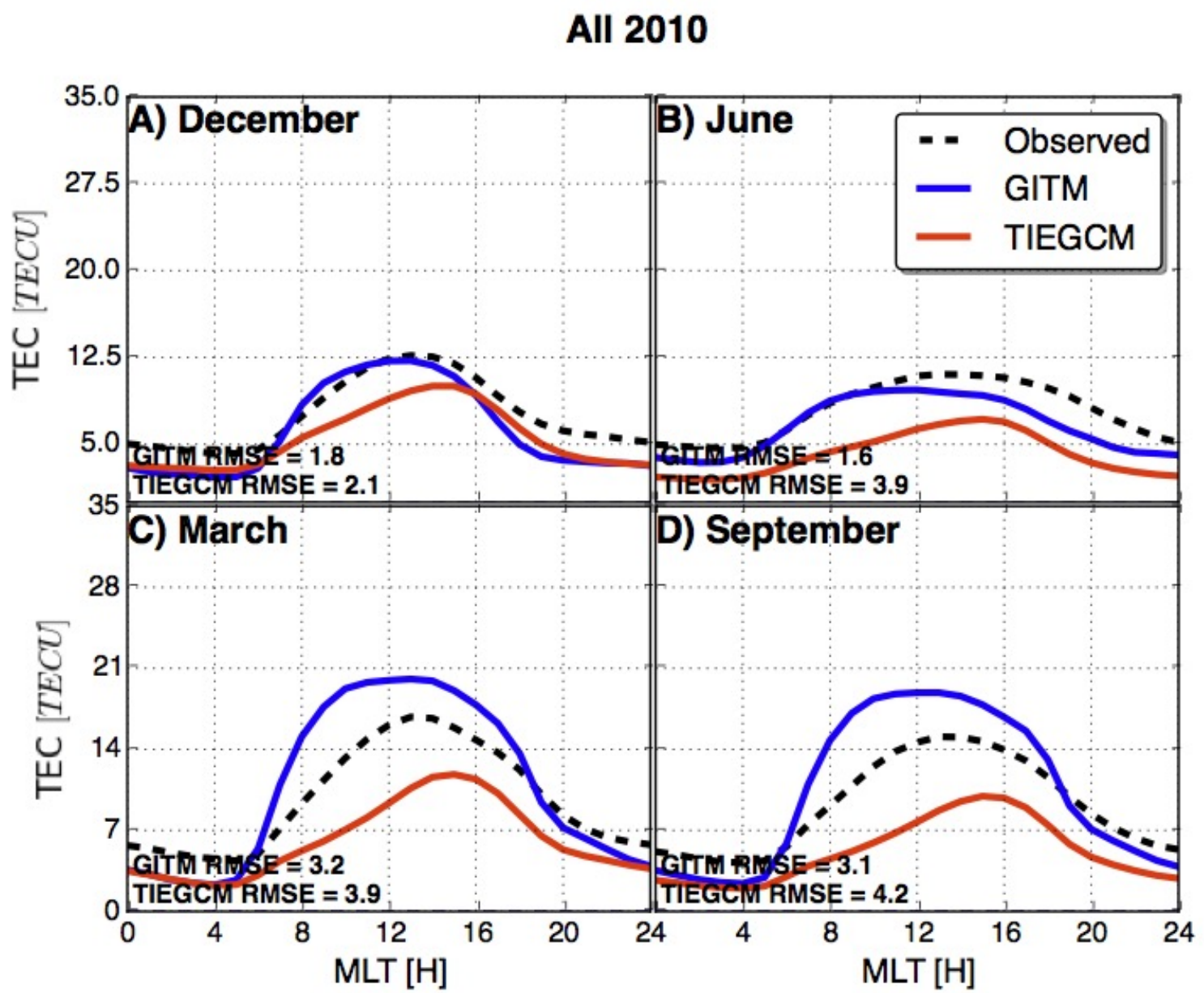

Figure 3. TEC in TECU versus MLT for both solstices at the top and equinoxes at the bottom. The results were averaged over the entire month and all latitudes for each plot. GITM is represented by blue, TIE-GCM by red, and GPS observations by the dashed black line. The RMSE for each model is displayed in the bottom left of each plot. 


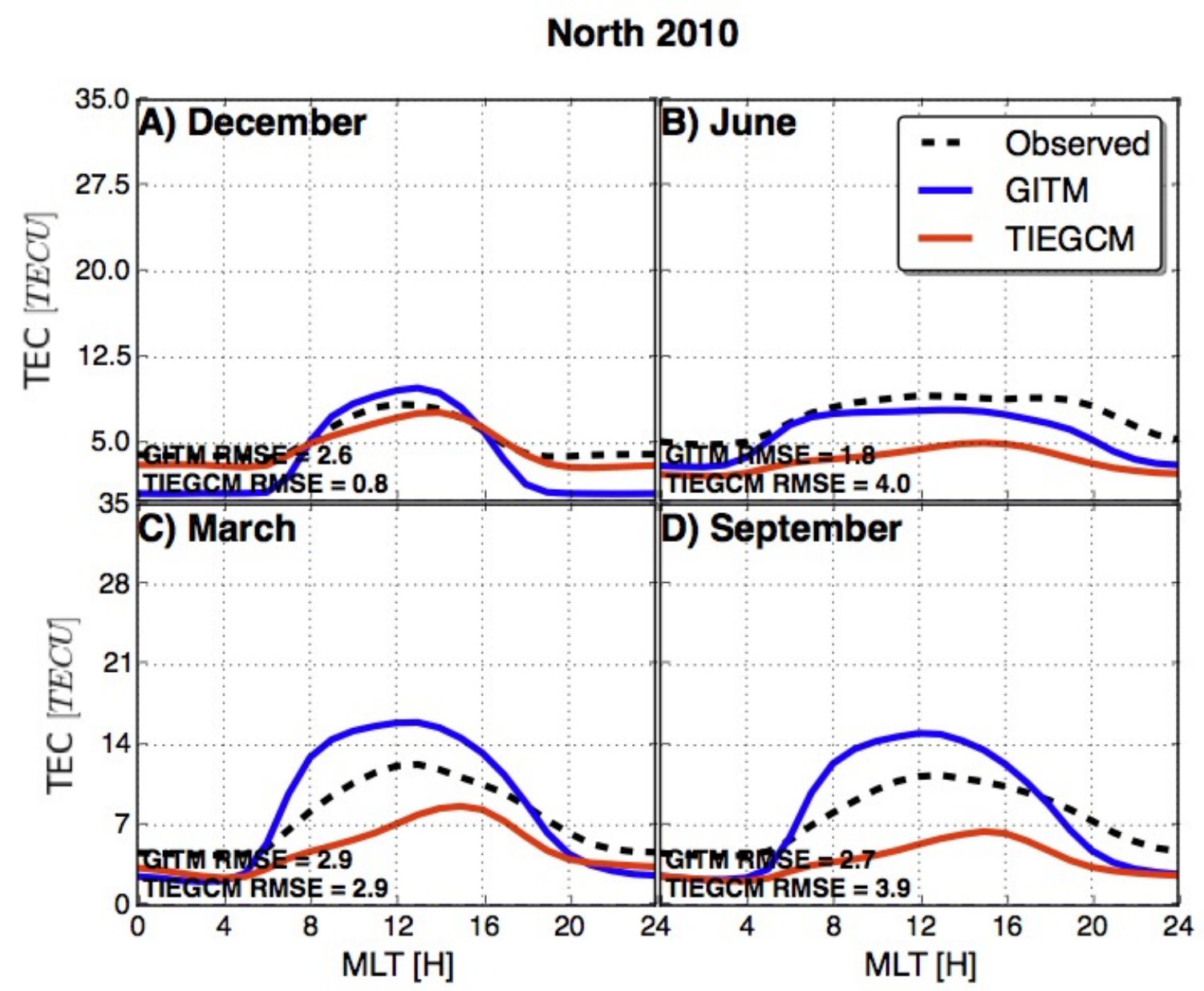

Figure 4. TEC in TECU versus MLT for both solstices at the top and equinoxes at the bottom for magnetic latitudes greater than $30^{\circ}$ in the northern hemisphere. The results were averaged over the entire month and all latitudes for each plot. GITM is represented by blue, TIE-GCM by red, and GPS observations by the dashed black line. The RMSE for each model is displayed in the bottom left of each plot. 


\section{South 2010}

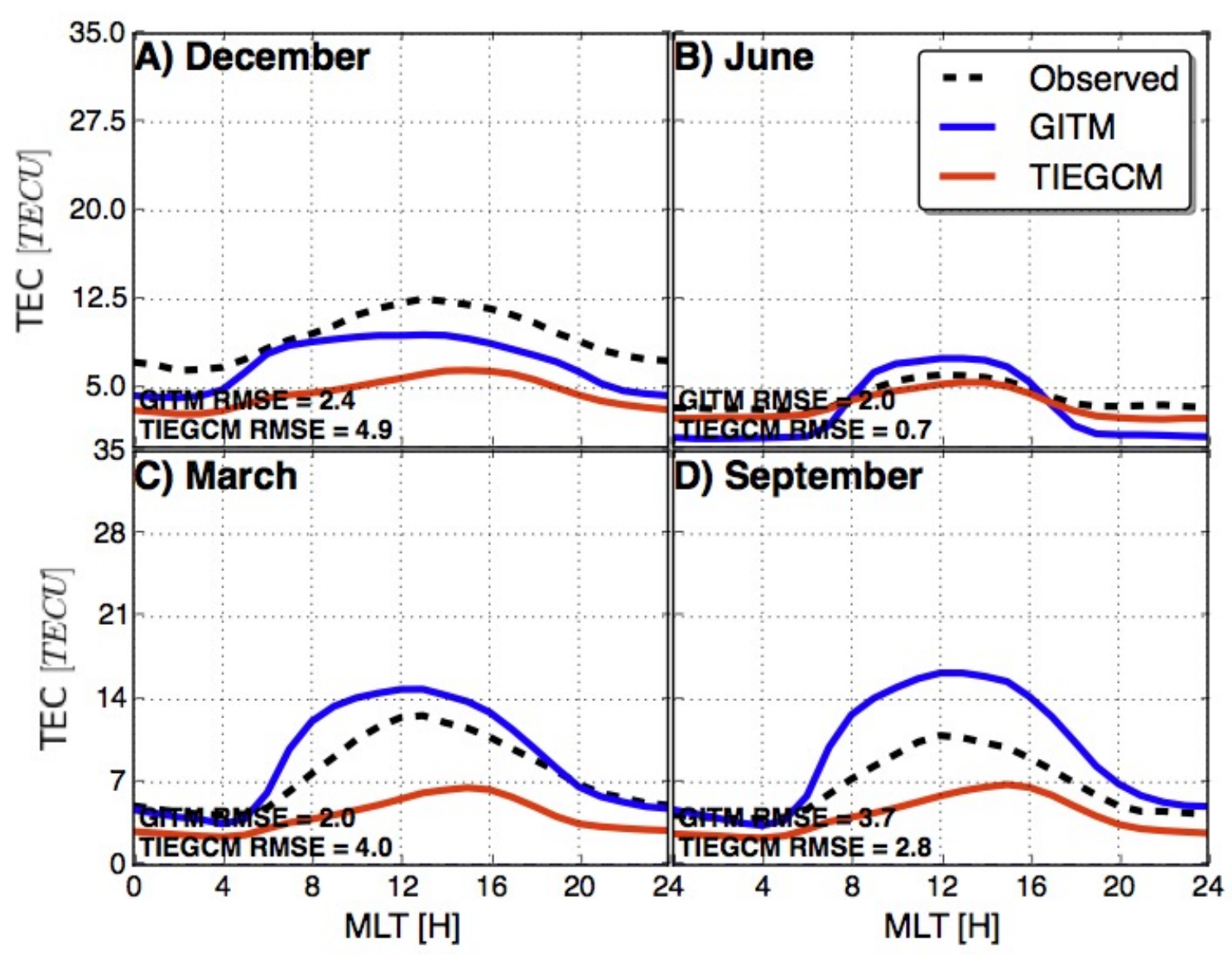

Figure 5. TEC in TECU versus MLT for both solstices at the top and equinoxes at the bottom for magnetic latitudes greater than $30^{\circ}$ in the southern hemisphere. The results were averaged over the entire month and all latitudes for each plot. GITM is represented by blue, TIE-GCM by red, and GPS observations by the dashed black line. The RMSE for each model is displayed in the bottom left of each plot. 
Eq 2010

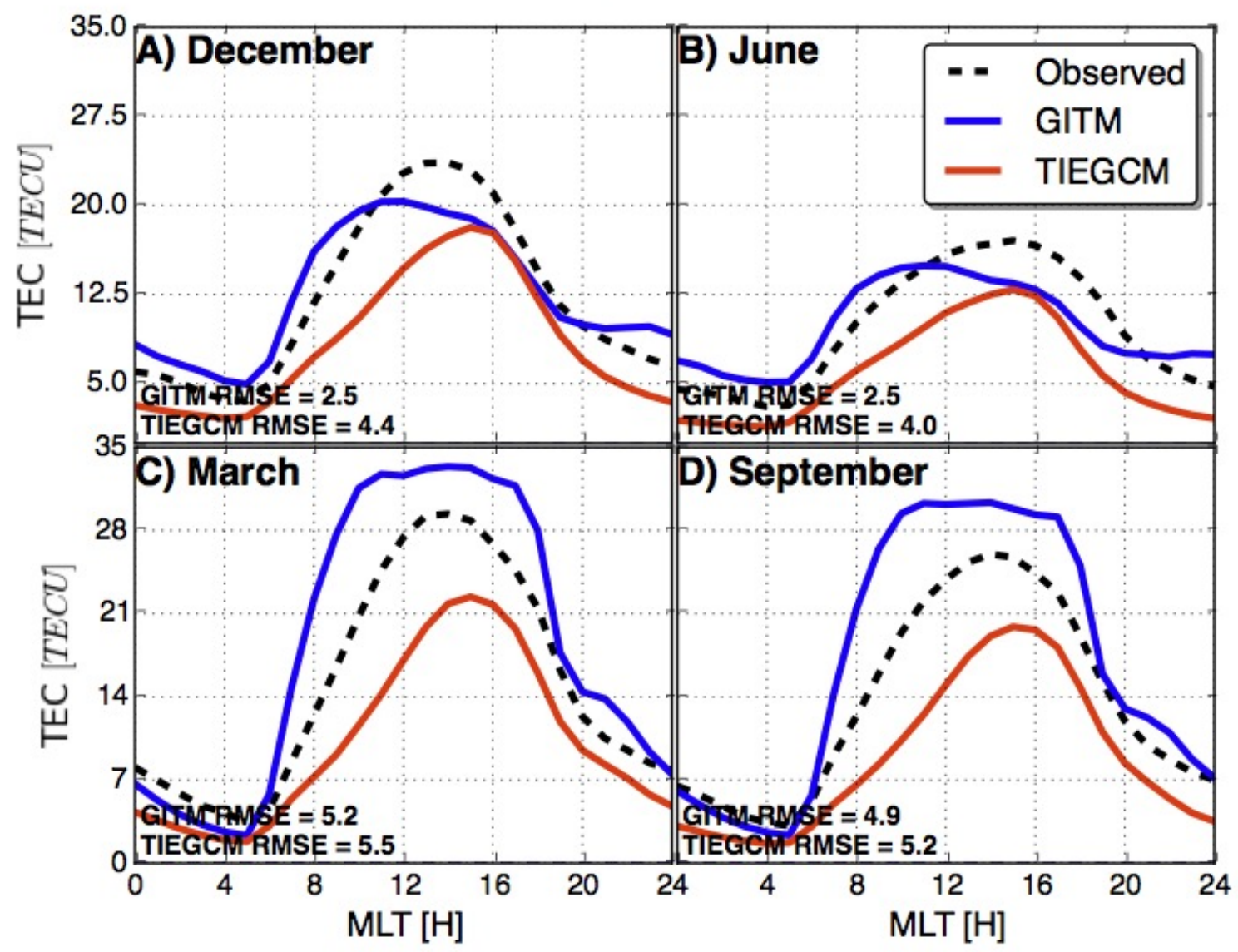

Figure 6. TEC in TECU versus MLT for both solstices at the top and equinoxes at the bottom for magnetic latitudes between $-30^{\circ}$ and $30^{\circ}$. . The results were averaged over the entire month and all latitudes for each plot. GITM is represented by blue, TIE-GCM by red, and GPS observations by the dashed black line. The RMSE for each model is displayed in the bottom left of each plot. 
plots/plot_NmF2_new.png

Figure 7. NmF2 for GITM, TIE-GCM, and ionosonde observations in the blue, red, and black dashed lines respectively. The columns show the results at 4 different locations distributed by latitude. Results are averaged over March in the top row and June in the bottom row. The labels in the top left corner of each subplot correspond to the analogous TEC model results from the indicated previous figure and subplots. 


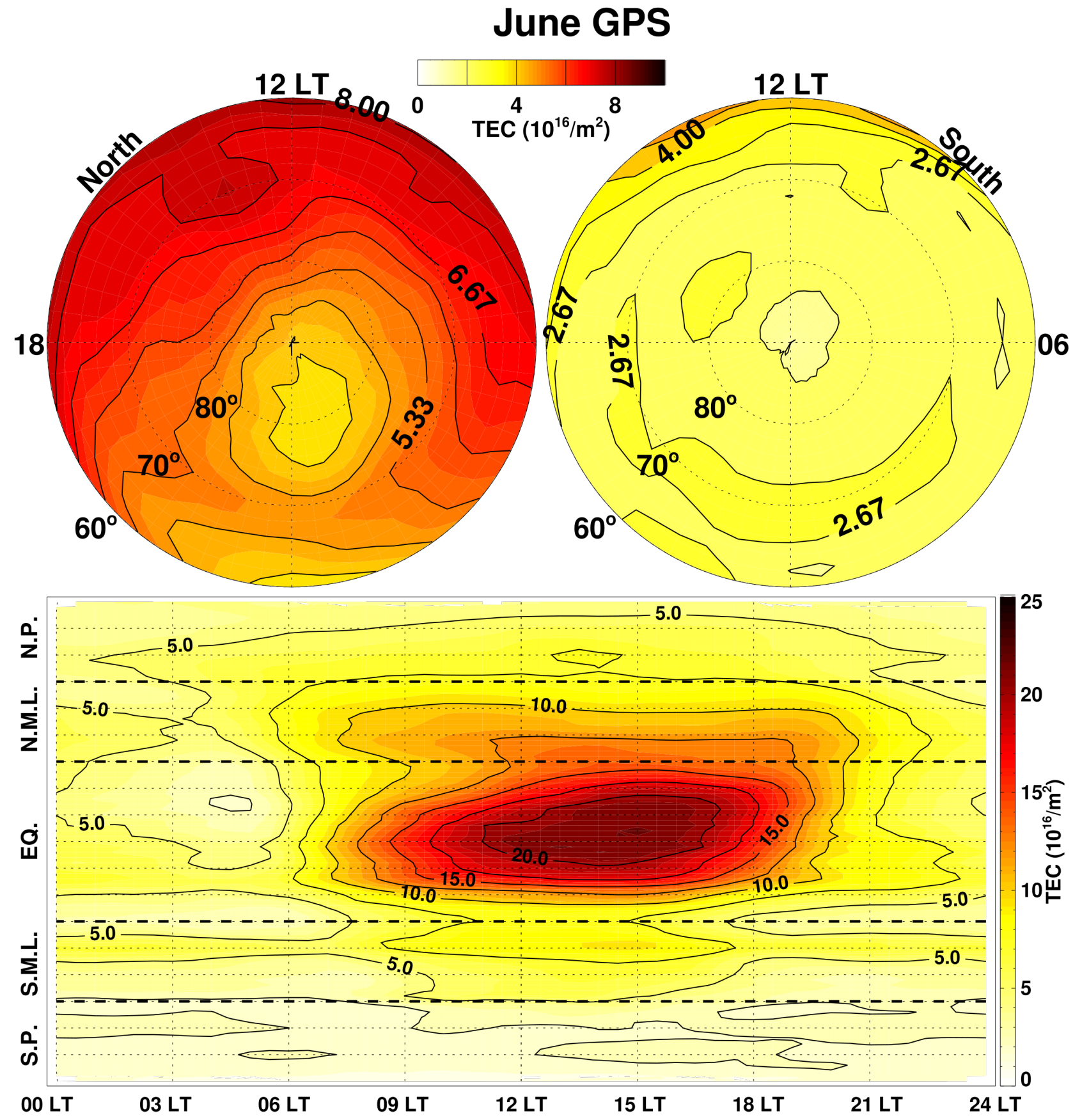

Figure 8. Global view of TEC for GPS observations averaged over the month of June, 2010. The polar plots are the northern (left) and southern (right) hemisphere's poleward of $60^{\circ}$ geomagnetic latitude. The rectangle plot is divided into the same latitude bins as Figure 2. The scale of the polar plots is half that of the rectangle plot. 


\section{June GITM}
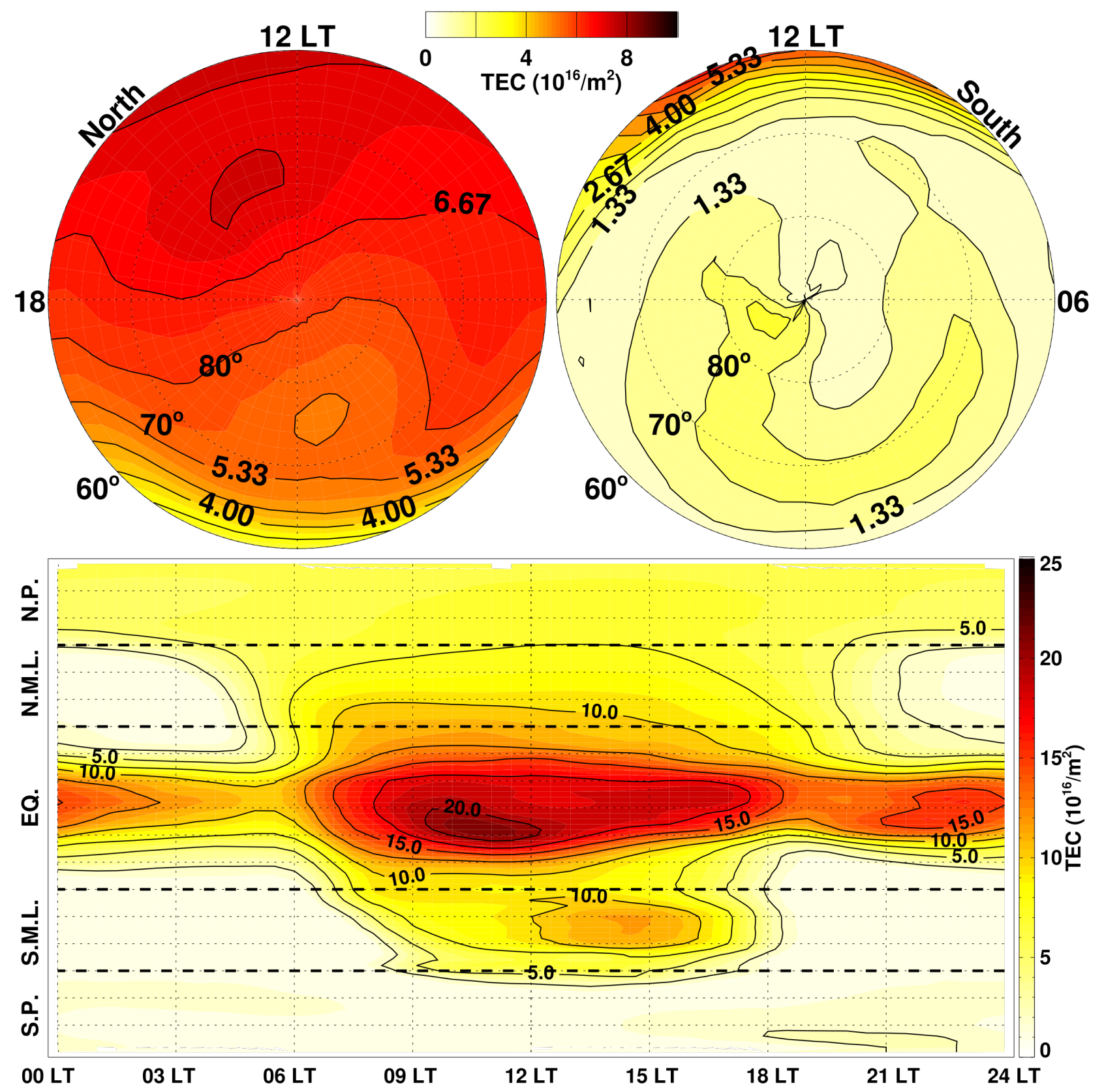

Figure 9. Global view of GITM TEC averaged over the month of June, 2010. The polar plots are the northern (left) and southern (right) hemisphere's poleward of $60^{\circ}$ geomagnetic latitude. The rectangle plot is divided into the same latitude bins as Figure 2. The scale of the polar plots is half that of the rectangle plot. 


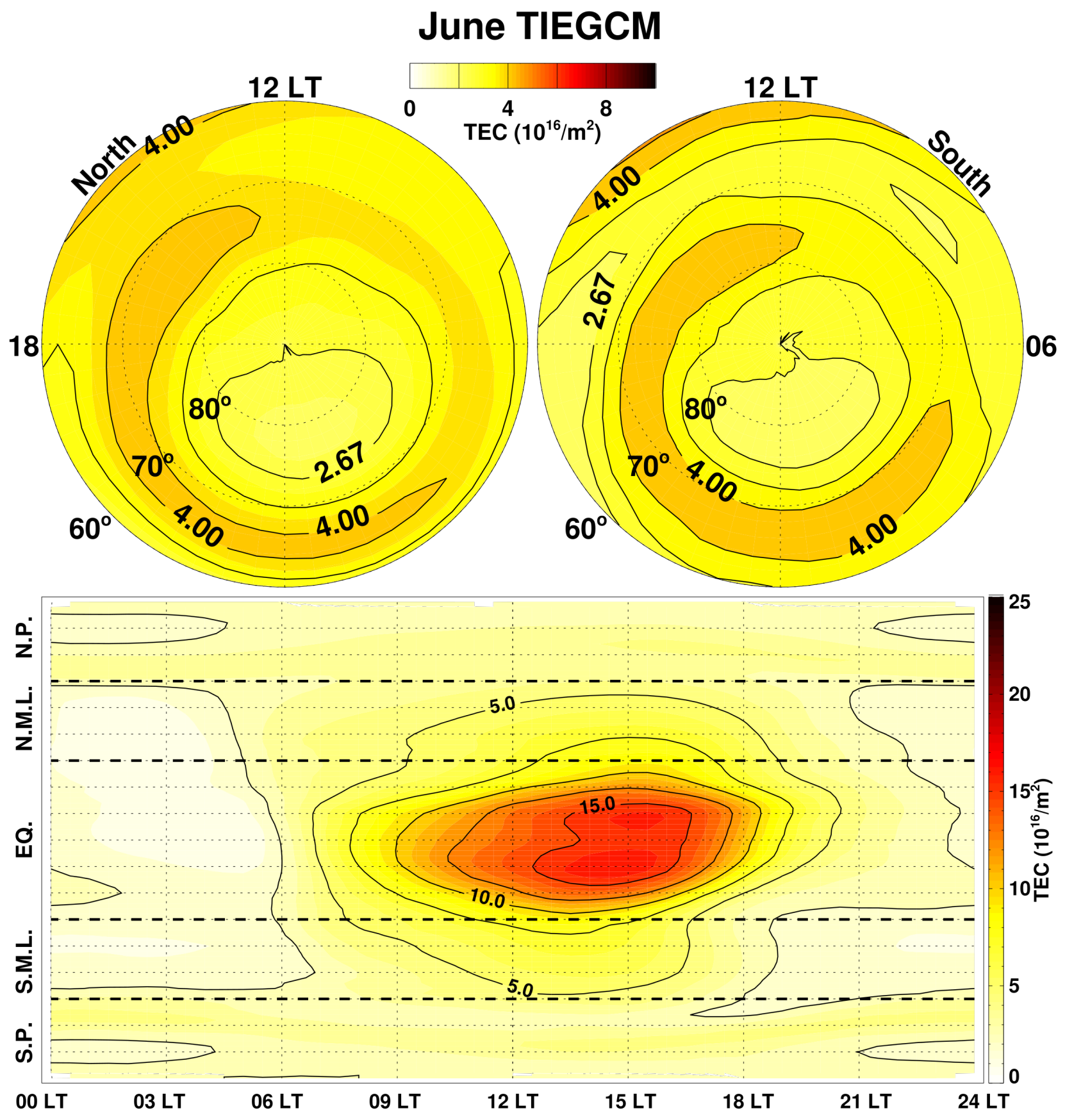

Figure 10. Global view of TIE-GCM TEC averaged over the month of June, 2010. The polar plots are the northern (left) and southern (right) hemisphere's poleward of $60^{\circ}$ geomagnetic latitude. The rectangle plot is divided into the same latitude bins as Figure 2. The scale of the polar plots is half that of the rectangle plot. 
March GPS

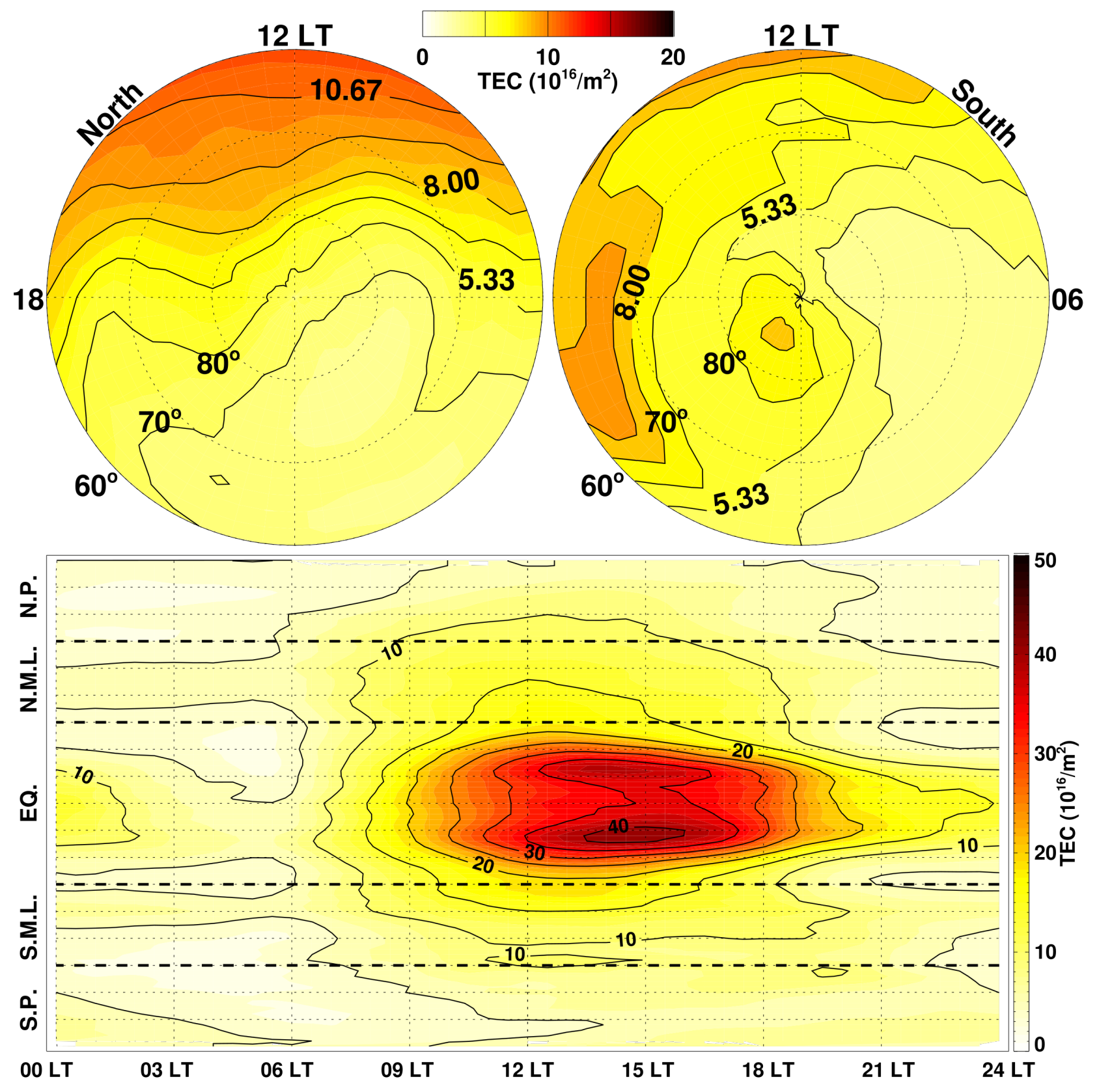

Figure 11. TEC for the GPS results averaged over March of 2010. Note that the scales are higher than the June figures. 


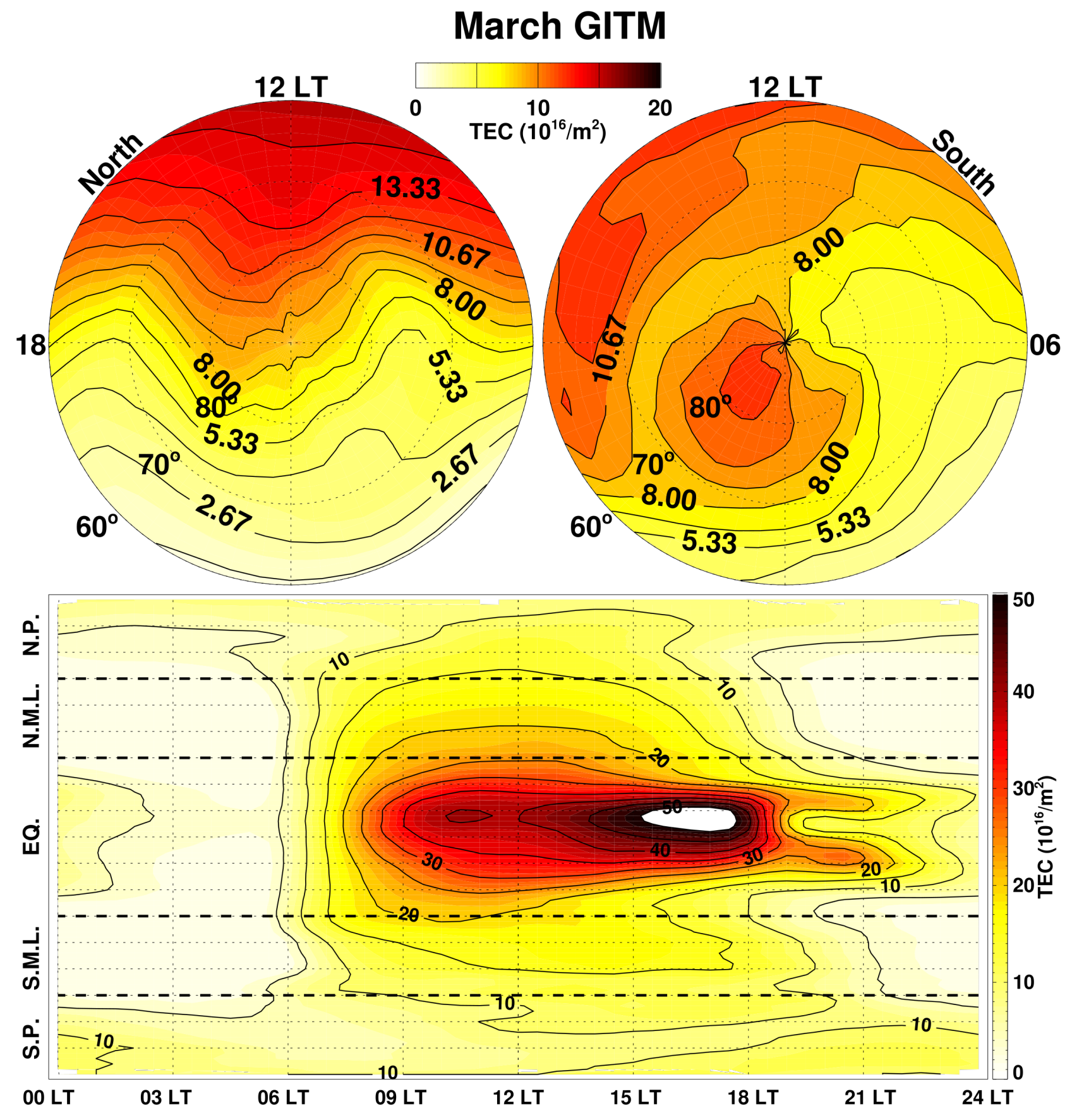

Figure 12. TEC for the GITM results averaged over March of 2010. 


\section{March TIEGCM}

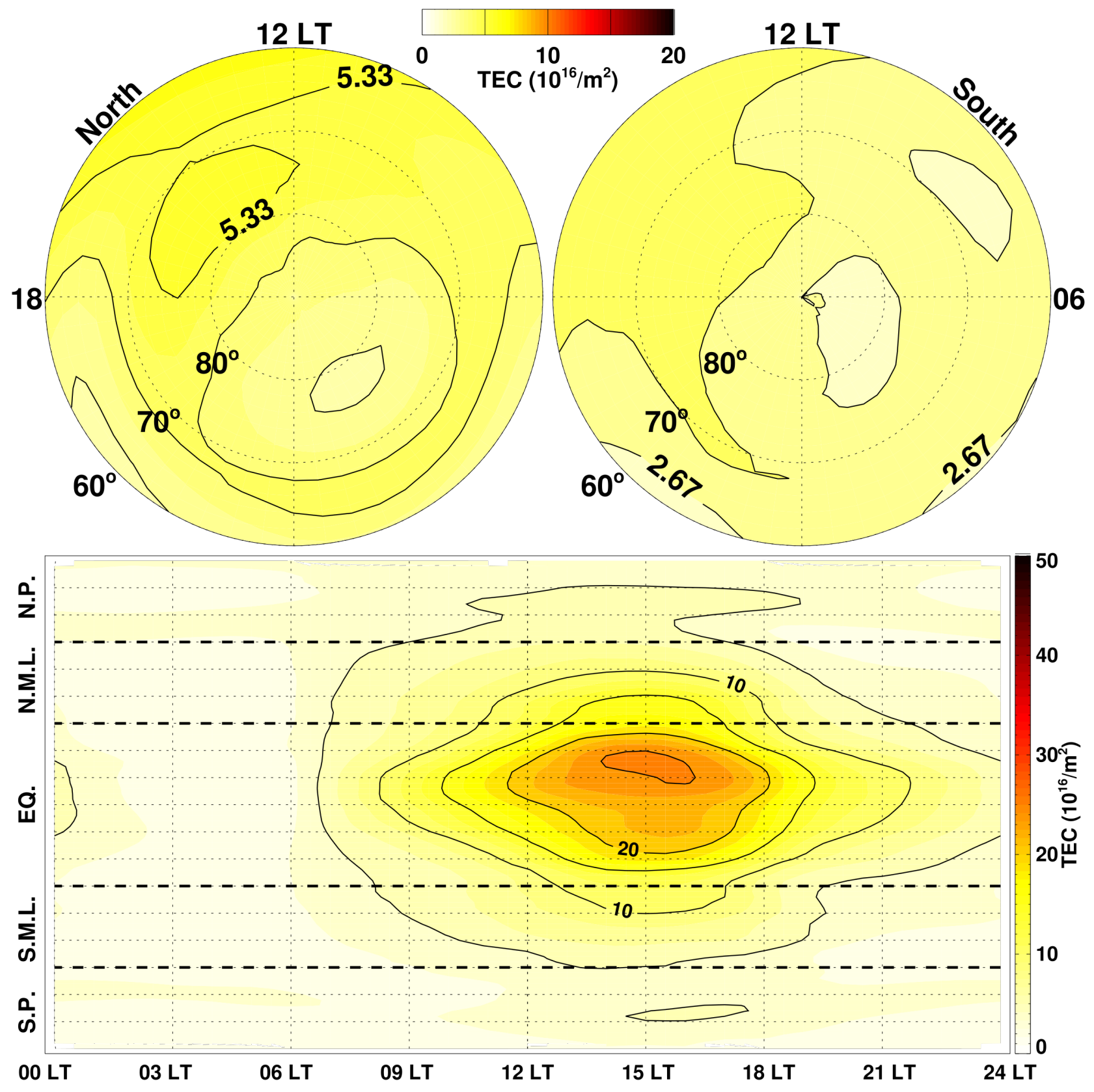

Figure 13. TEC for the TIE-GCM results averaged over March of 2010. 


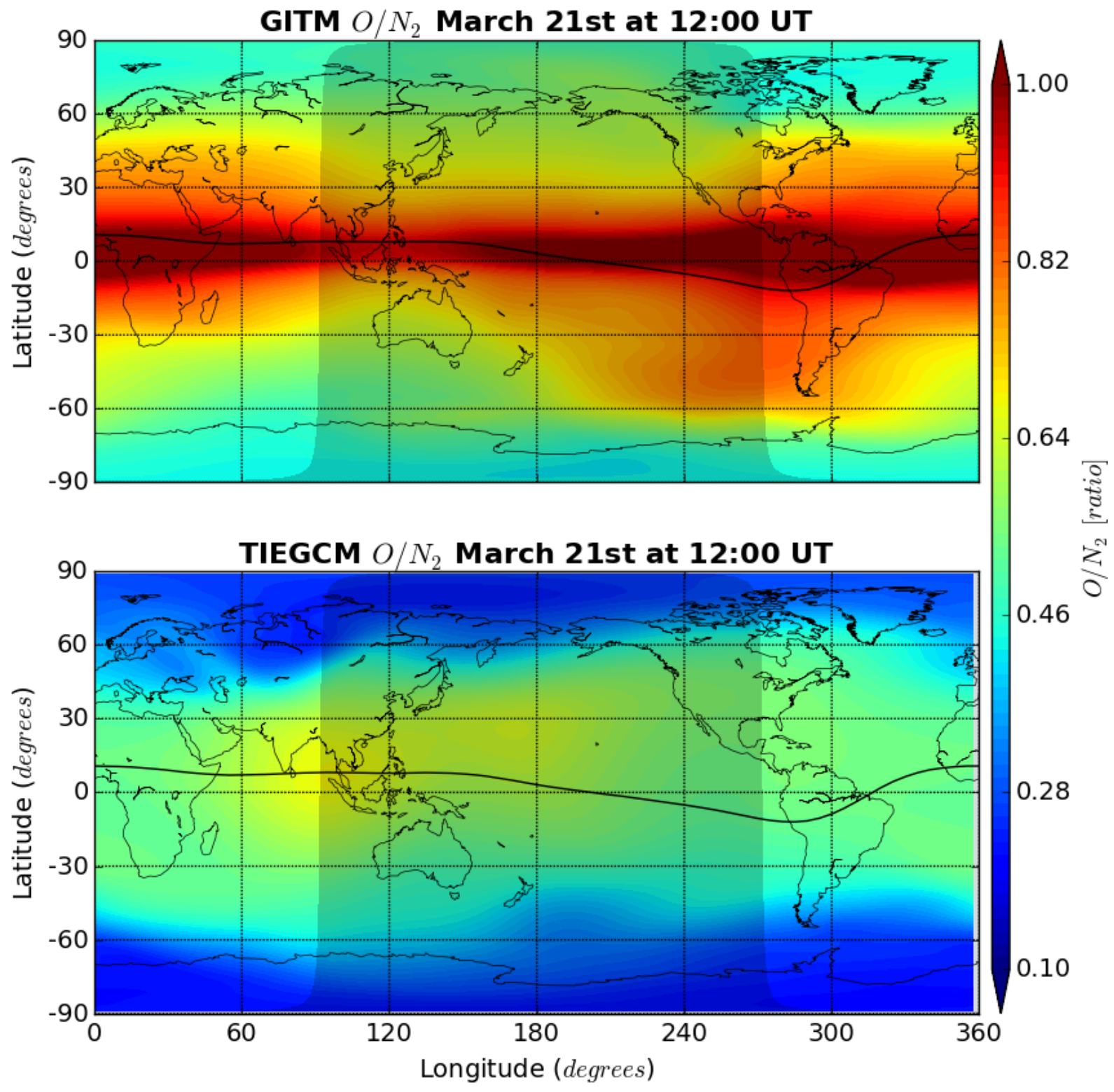

Figure 14. $\mathrm{O} / \mathrm{N}_{2}$ ratio for GITM at the top and TIE-GCM at the bottom at 12 UT on March 21st, 2010. The solid black line is the geomagnetic equator. The nightside is indicated by the shaded region. 


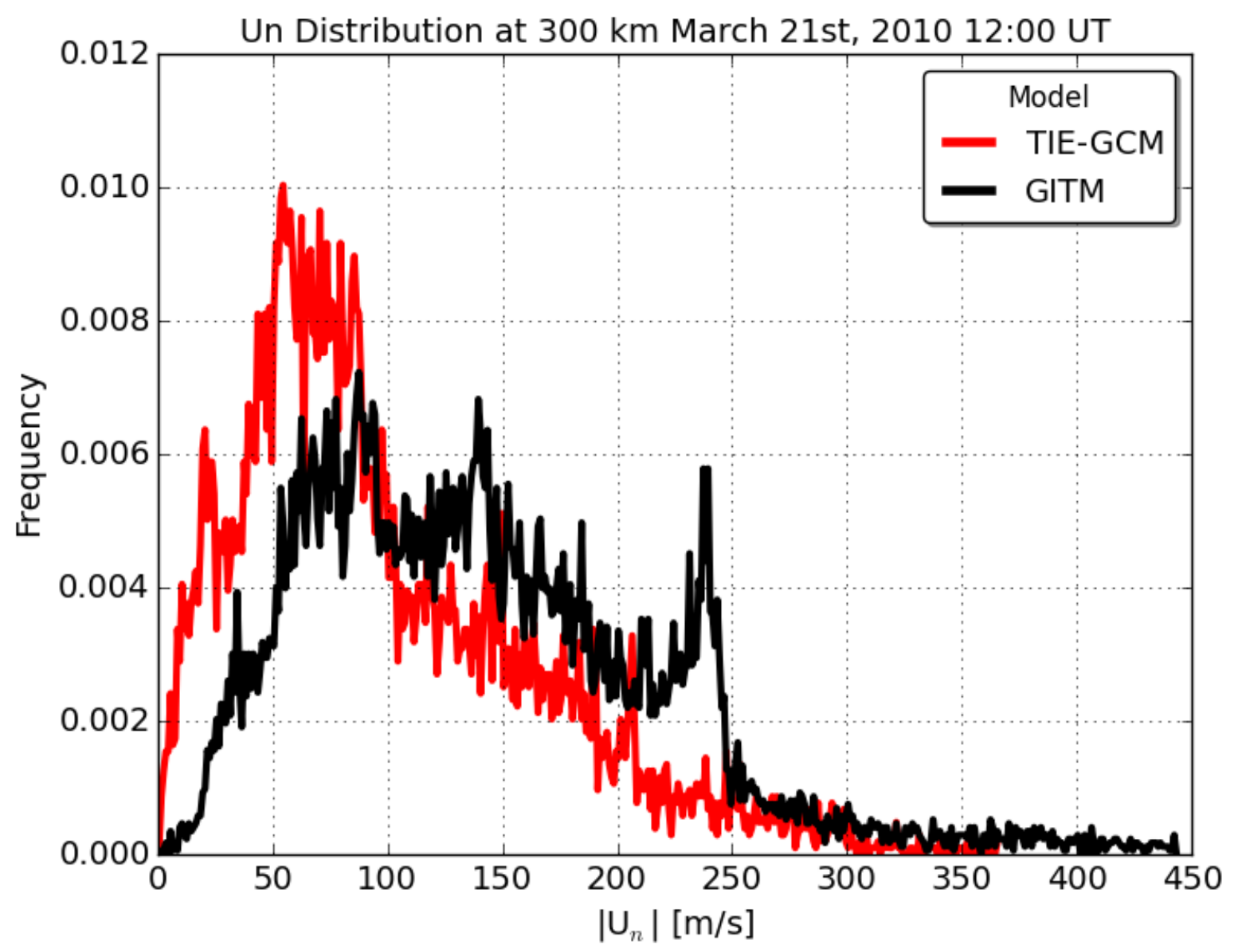

Figure 15. Distributions of the neutral wind magnitude for GITM in black and TIE-GCM in red at $300 \mathrm{~km}$. These were calculated at 12 UT on March 21st, 2010. 


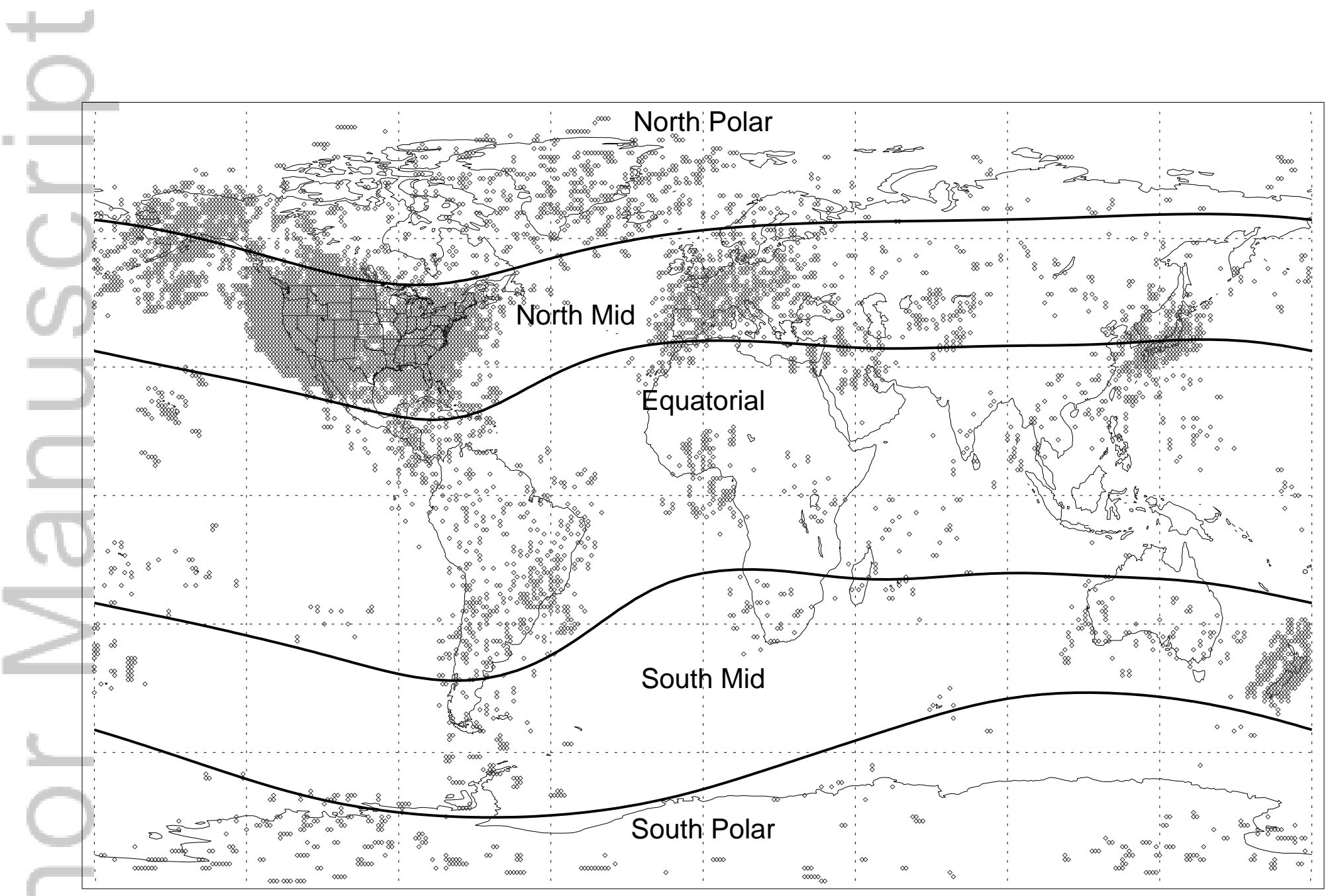

This article is protected by copyright. All rights reserved. 
Figure 2.
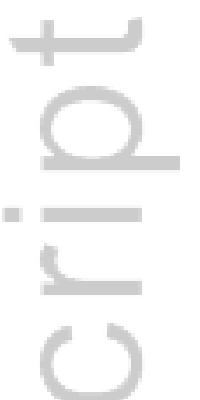

$\infty$
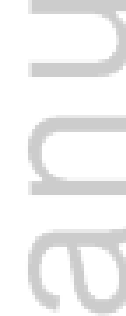

This article is protected by copyright. All rights reserved. 


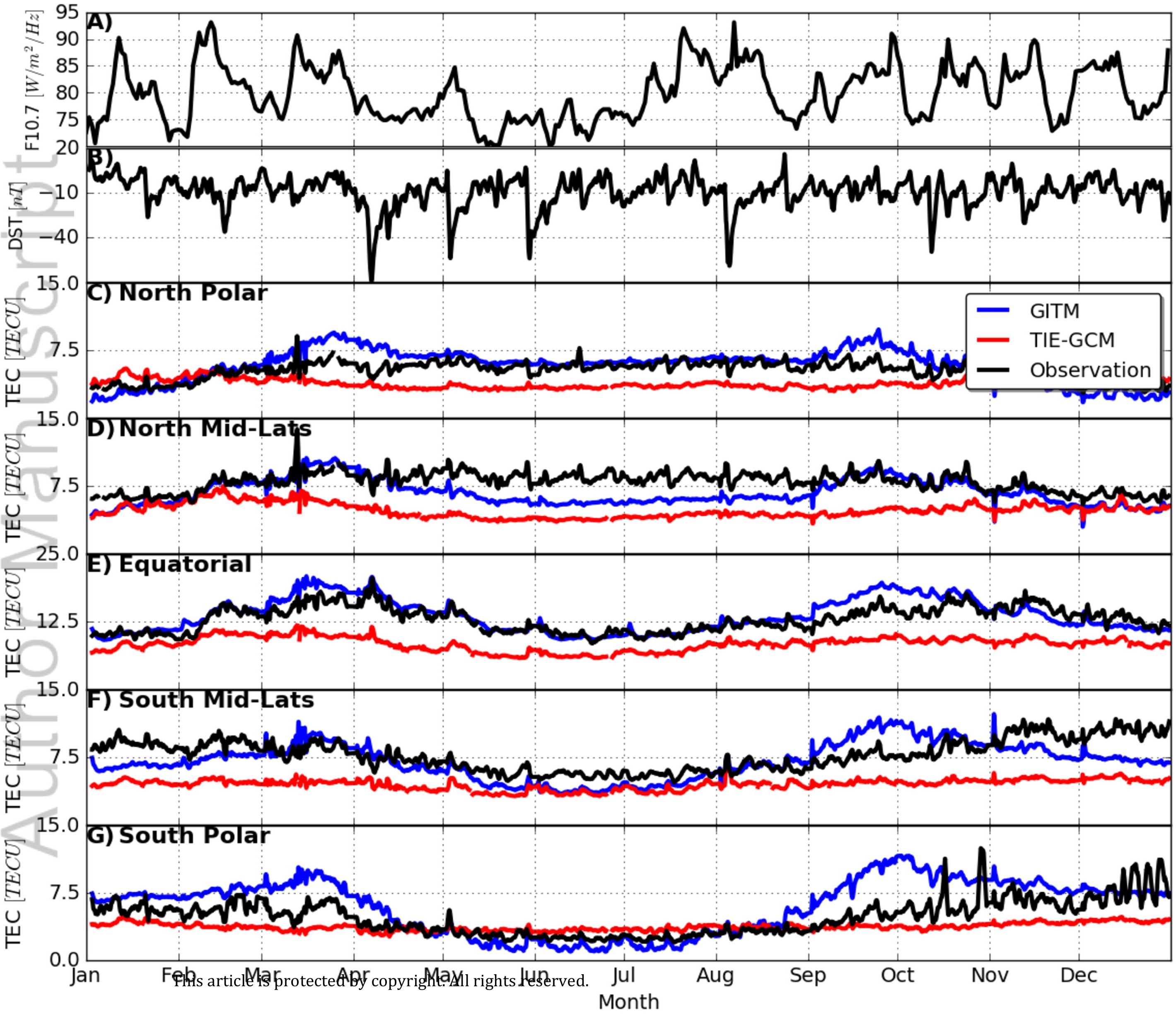


All 2010

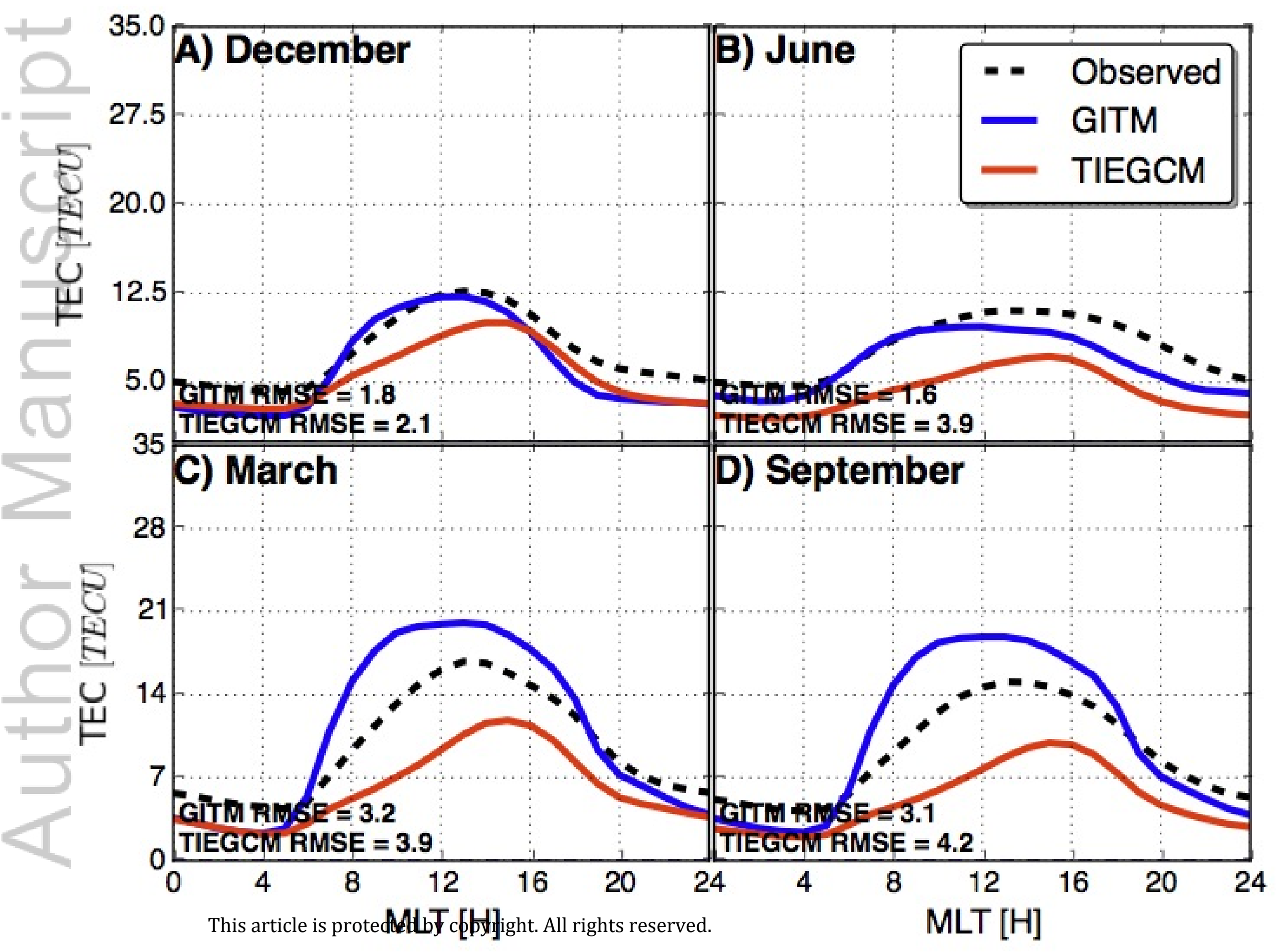




\section{North 2010}

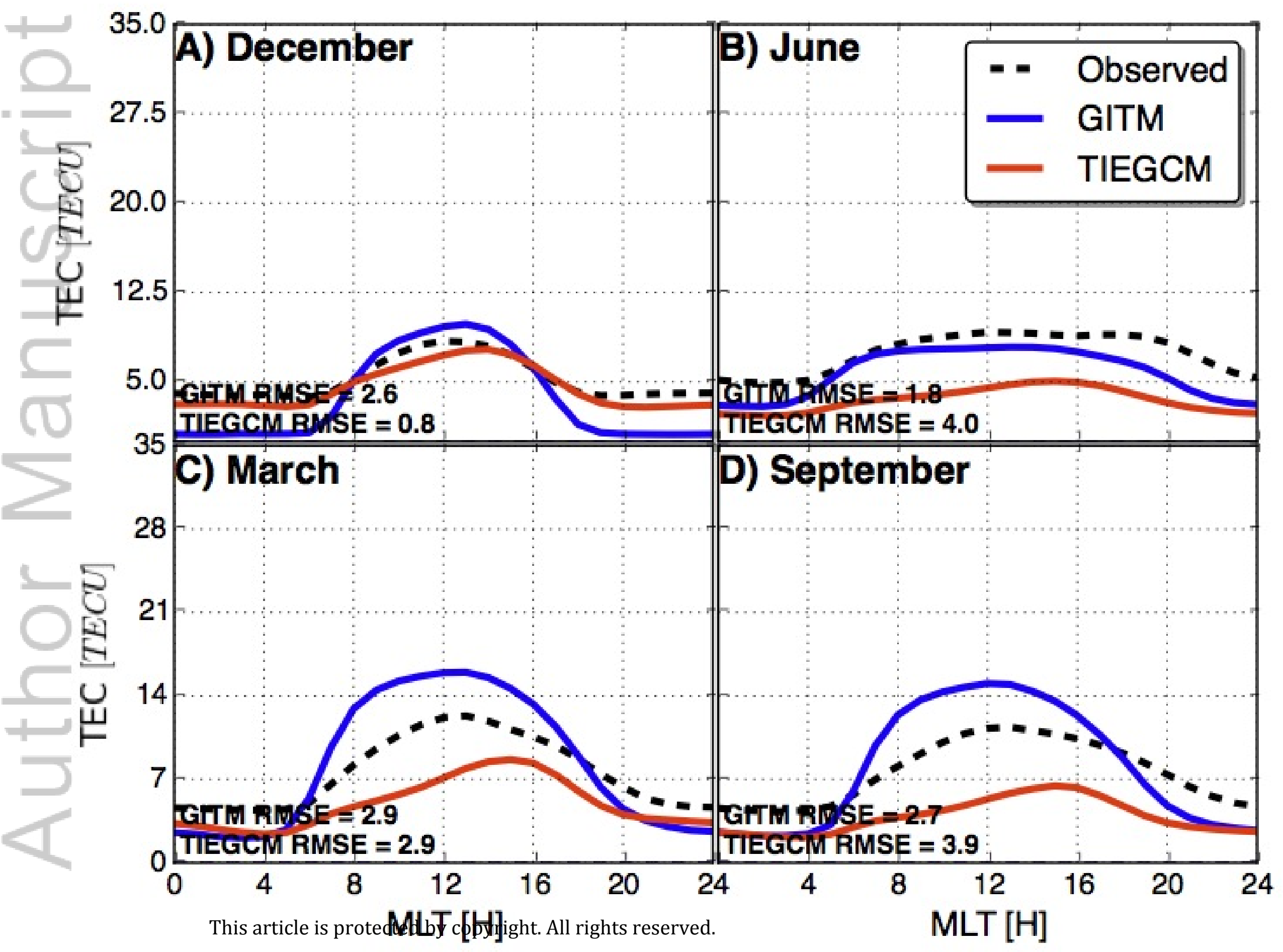


Figure 5.
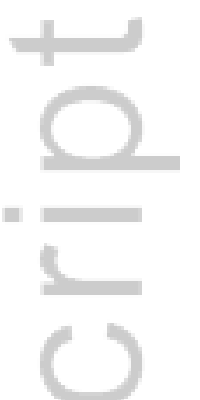

$\infty$
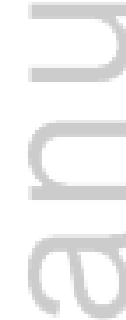

This article is protected by copyright. All rights reserved. 
South 2010

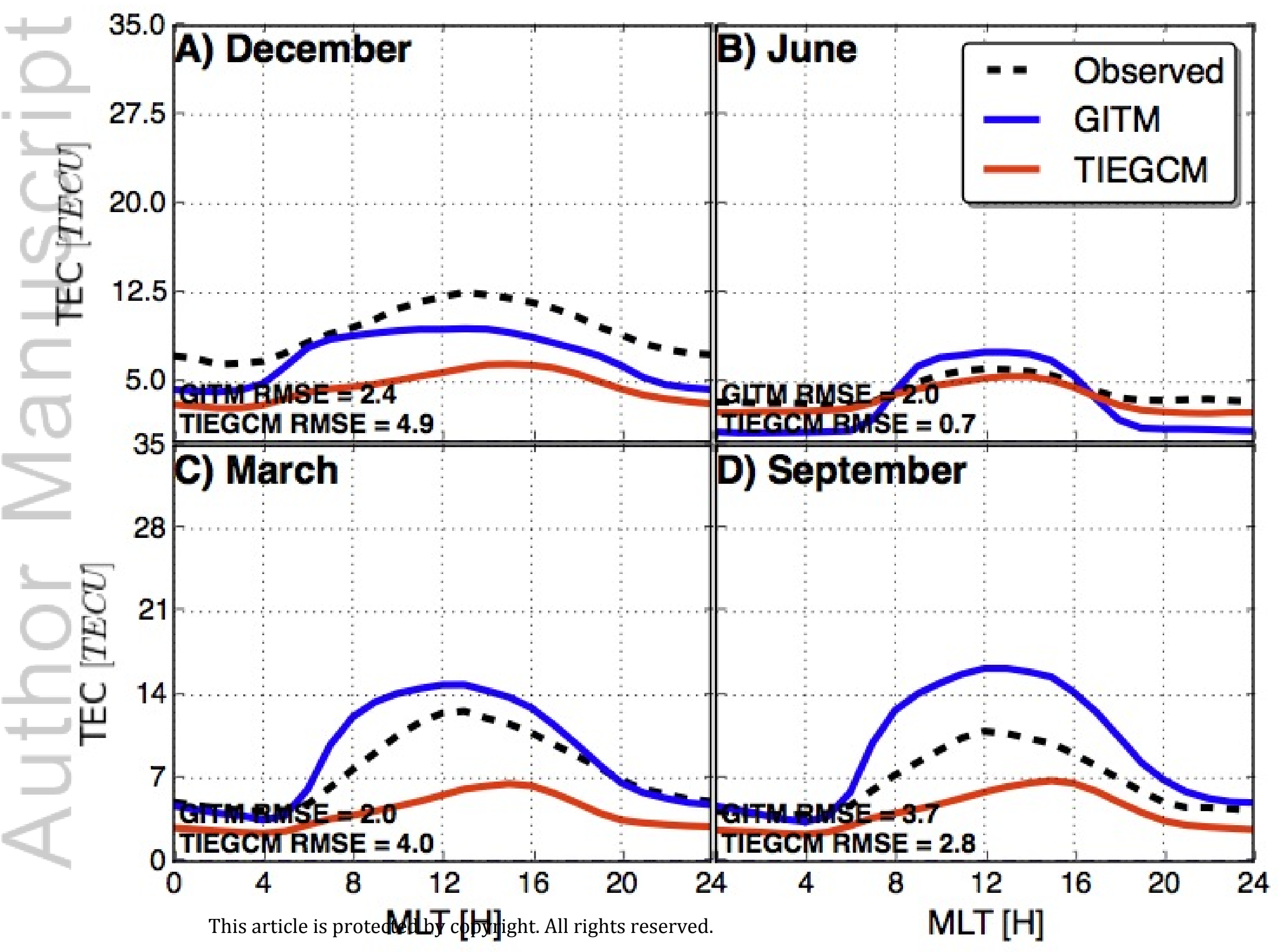


Eq 2010

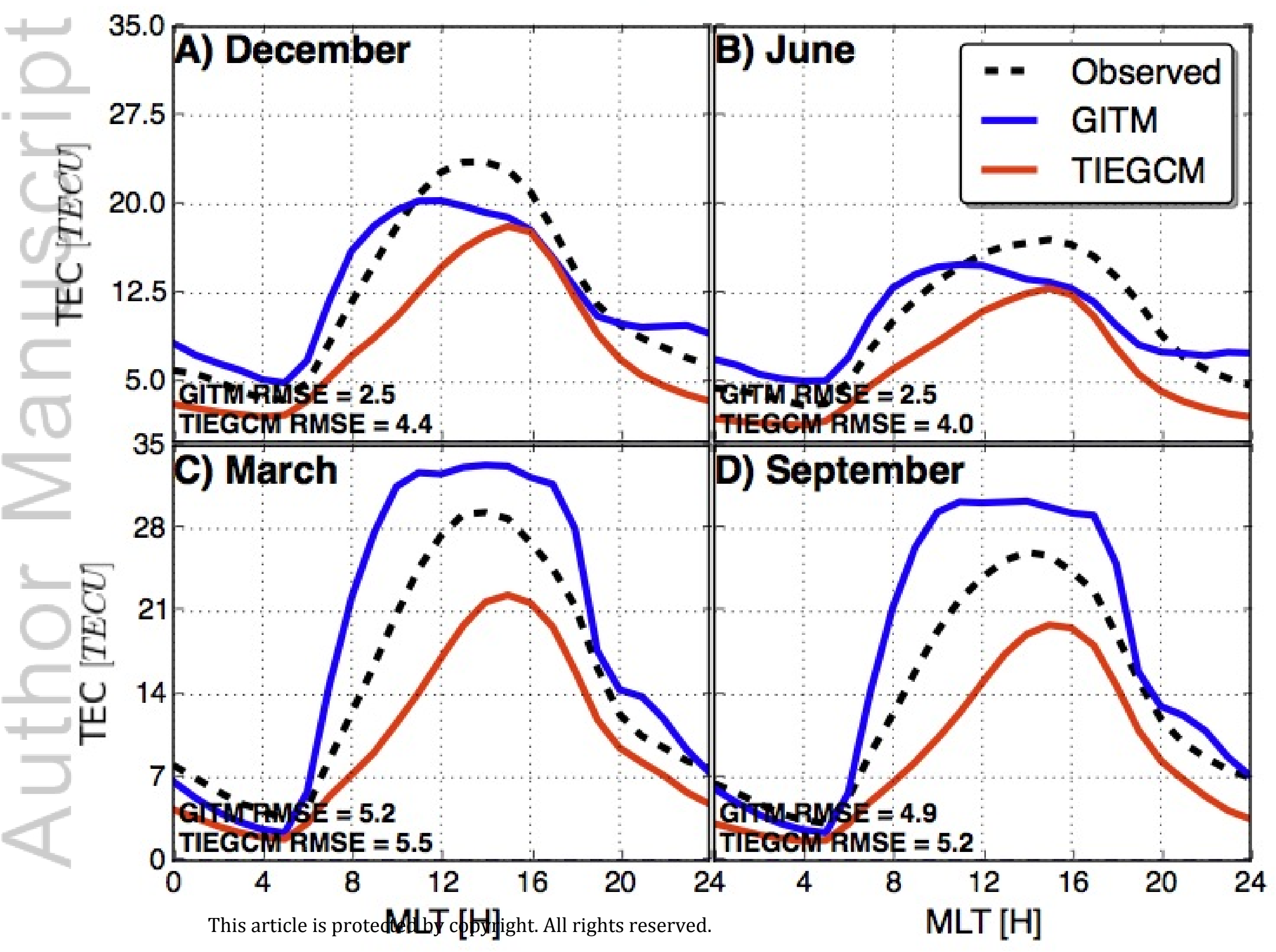




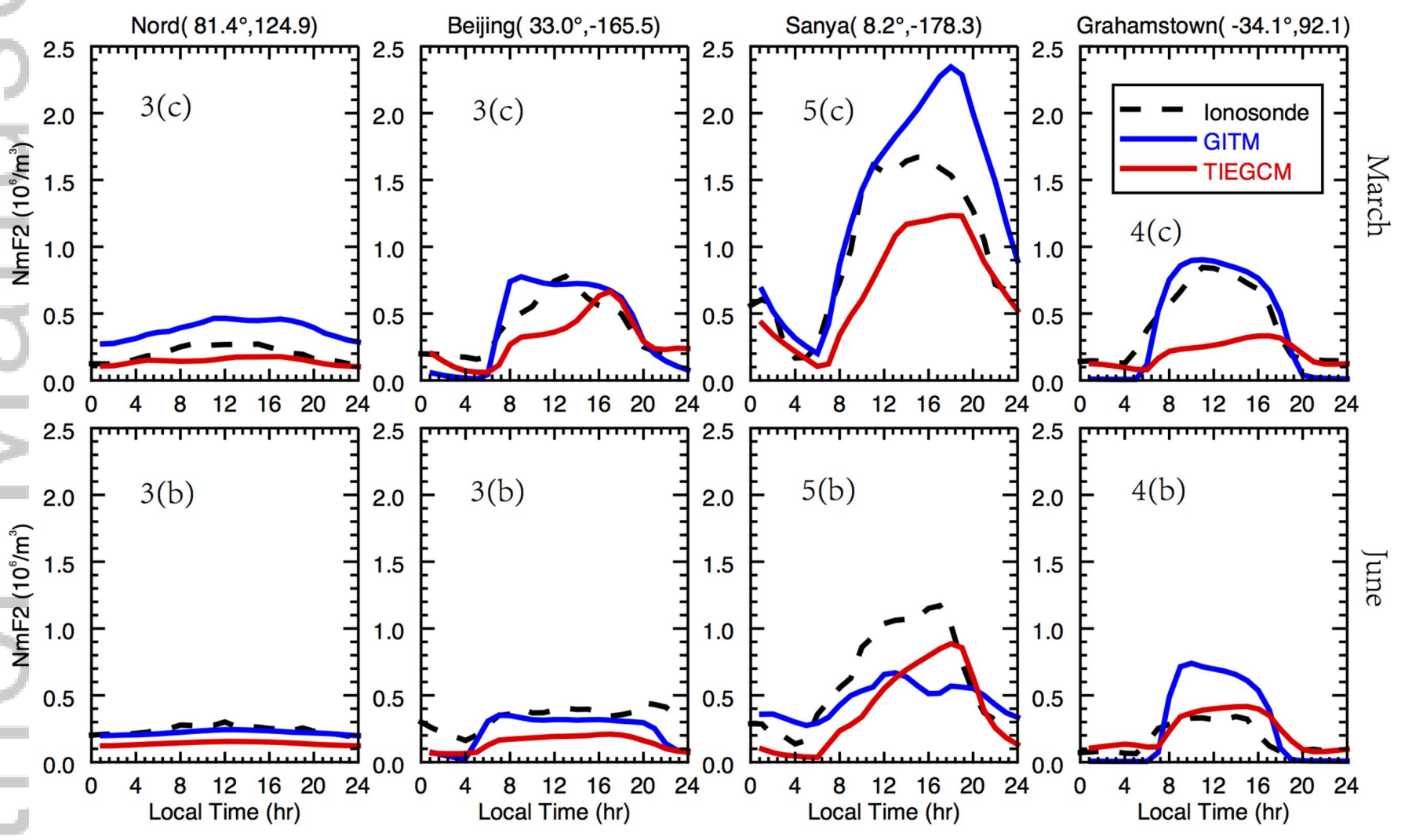

This article is protected by copyright. All rights reserved. 


\section{June GPS}

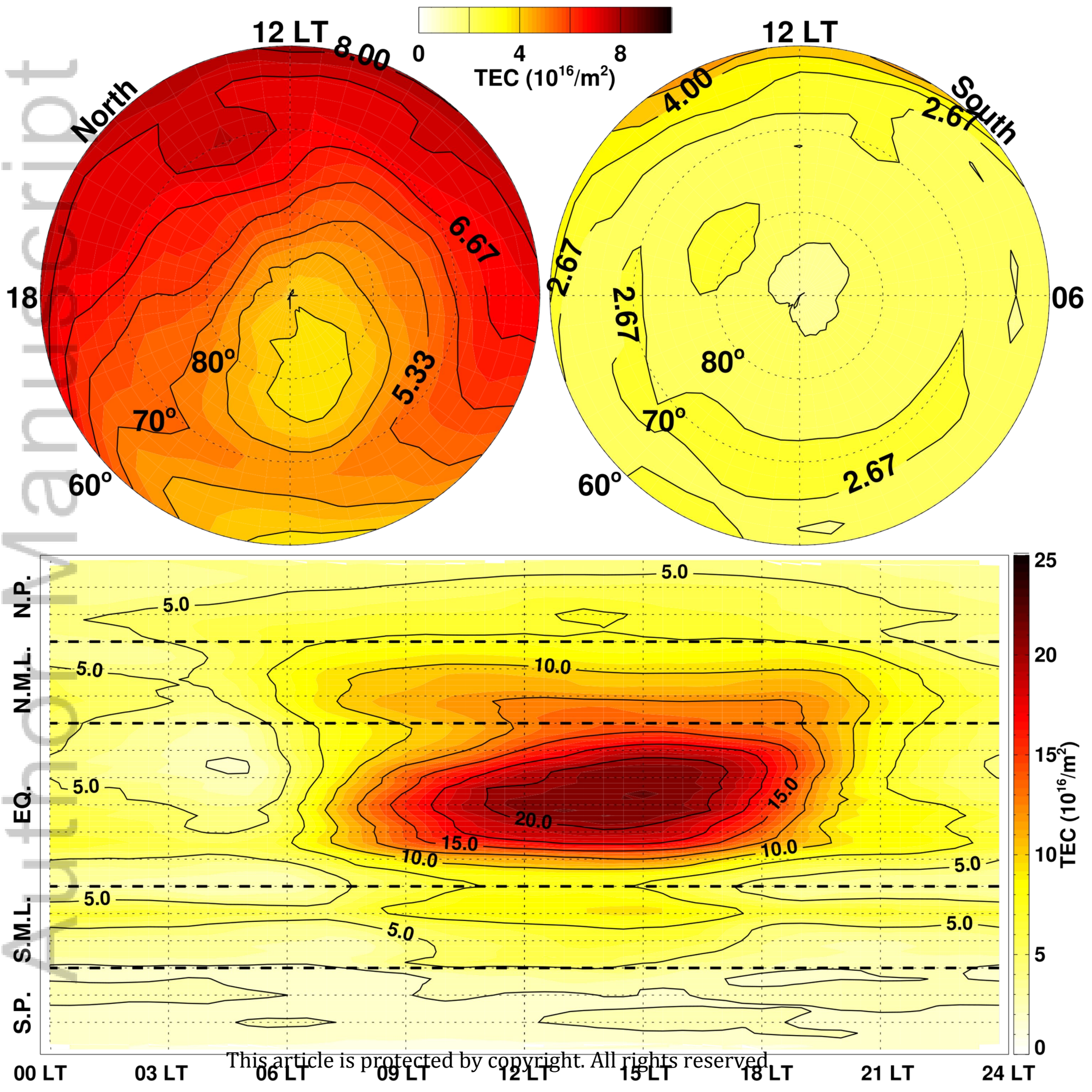


Figure 9.
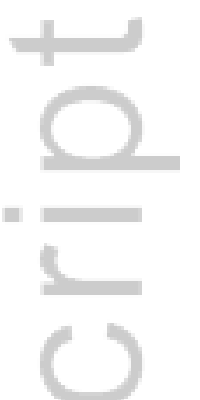

$\infty$
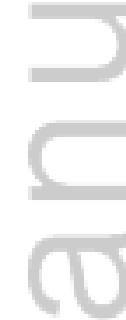

This article is protected by copyright. All rights reserved. 


\section{June TIEGCM}

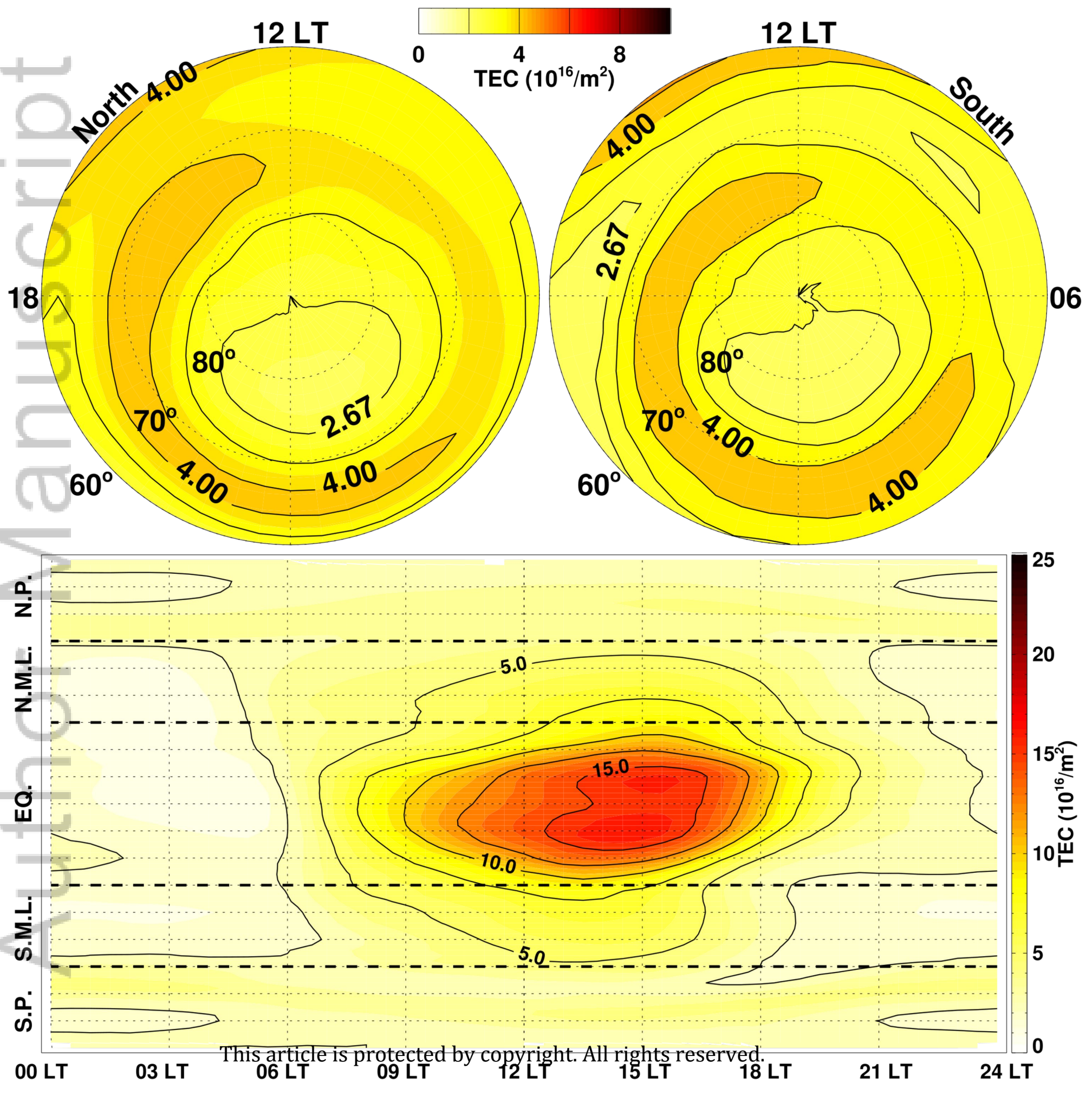




\section{March GPS}

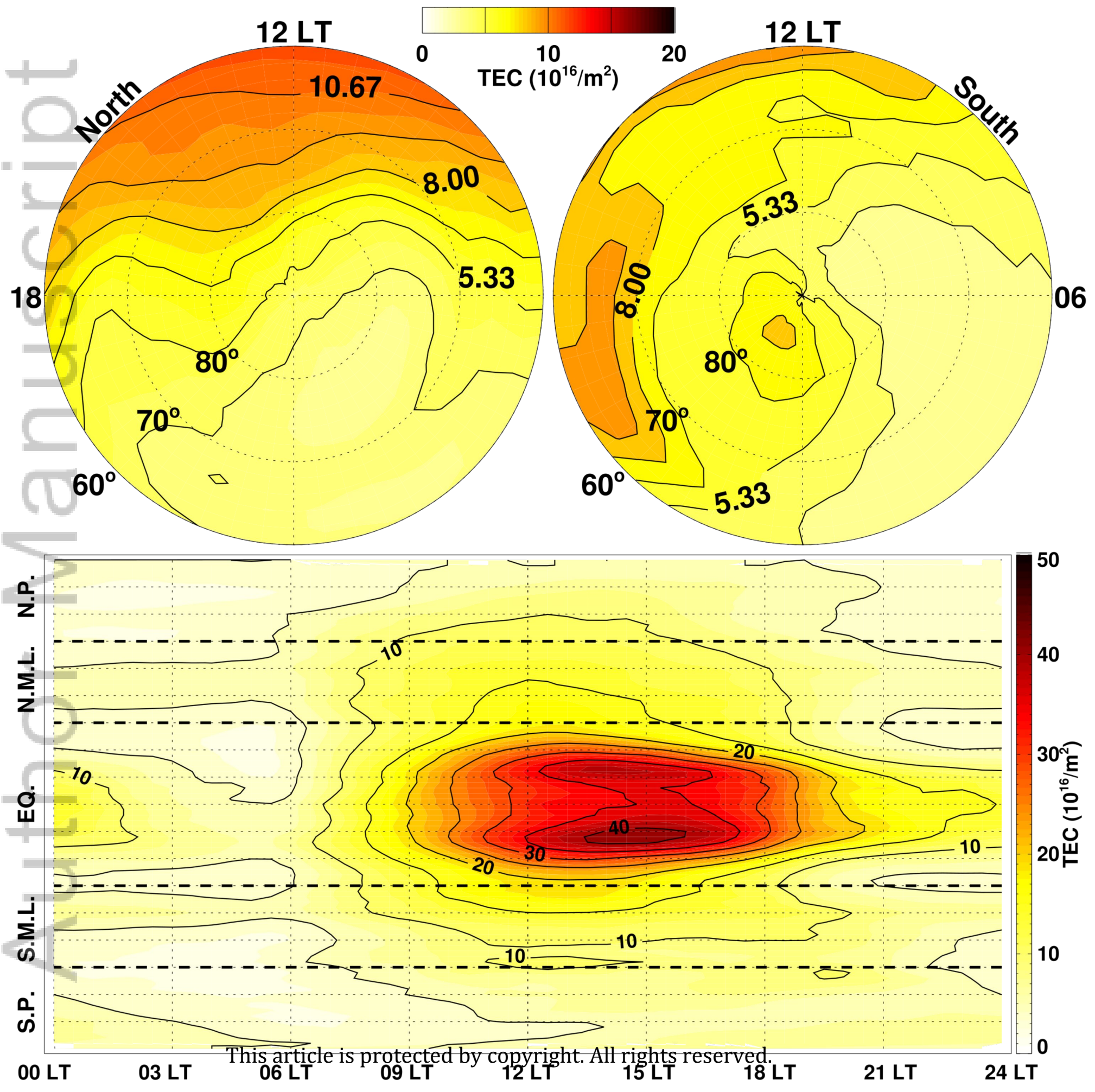


Figure 12.
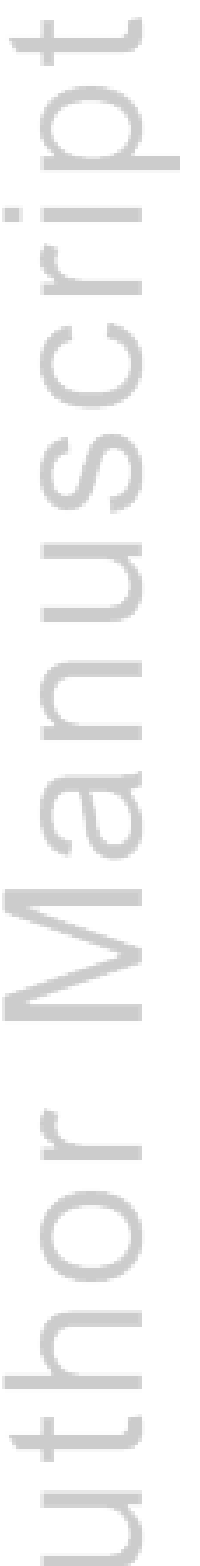

This article is protected by copyright. All rights reserved. 


\section{March GITM}

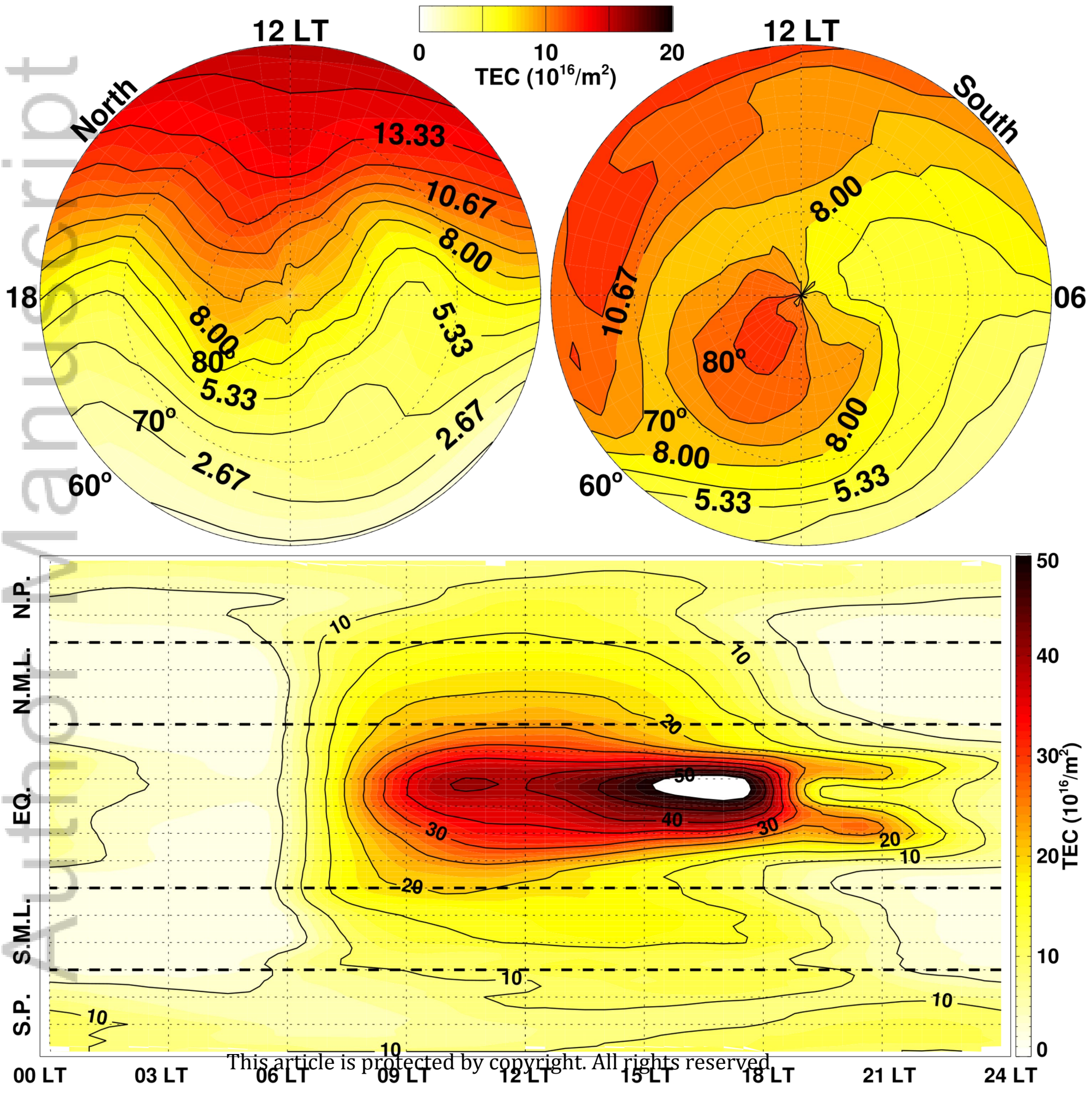




\section{March TIEGCM}

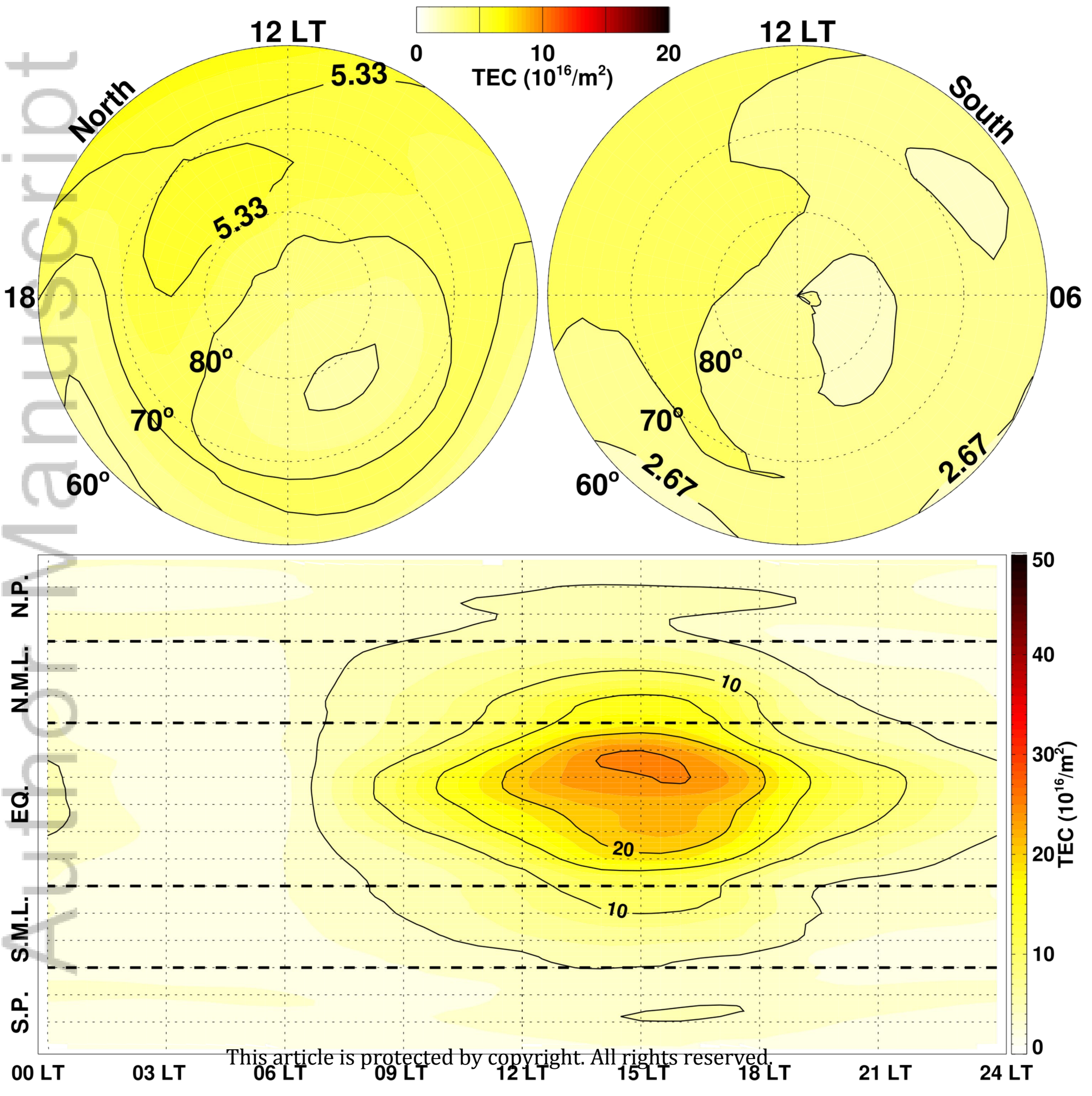




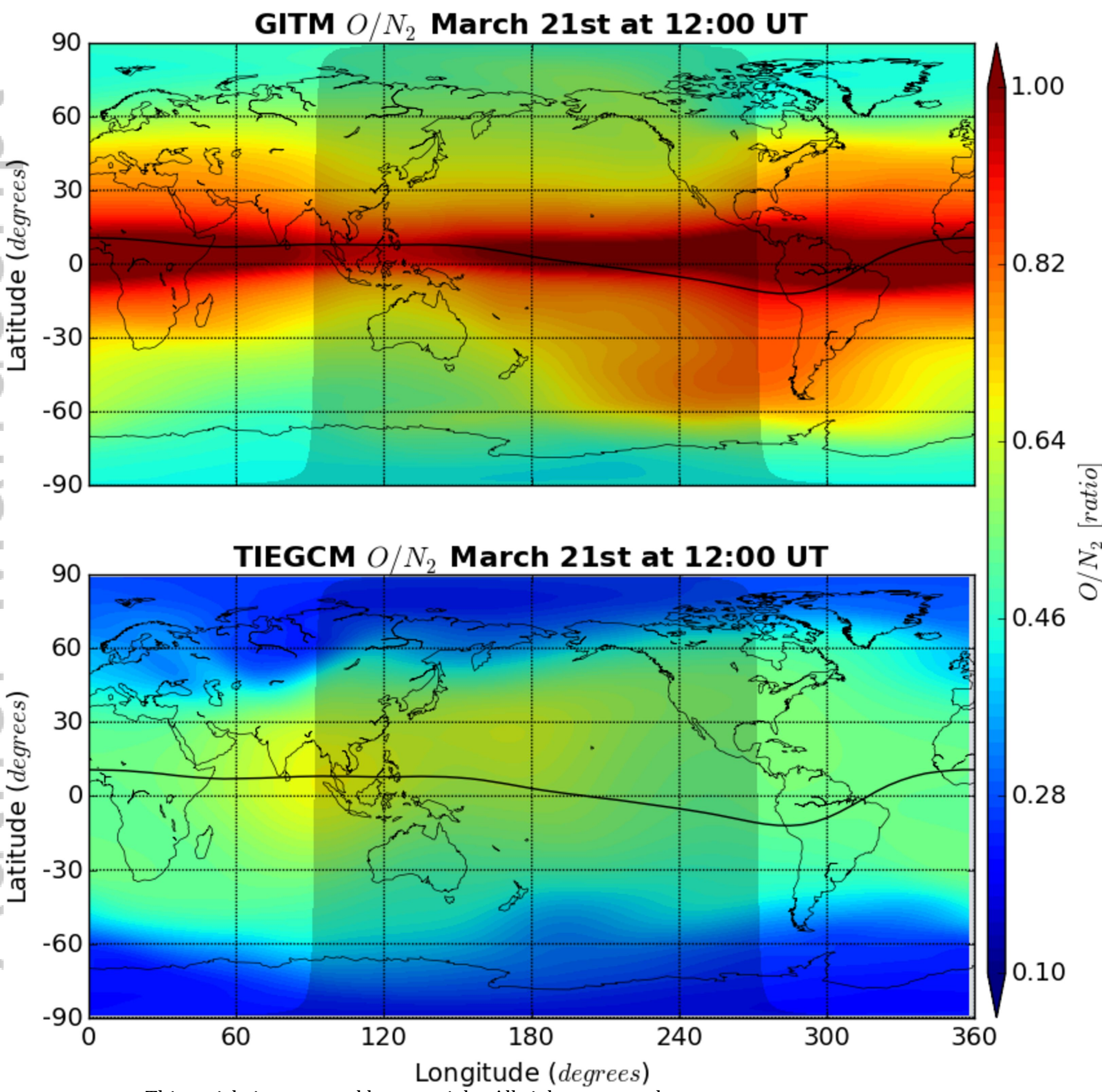

This article is protected by copyright. All rights reserved. 


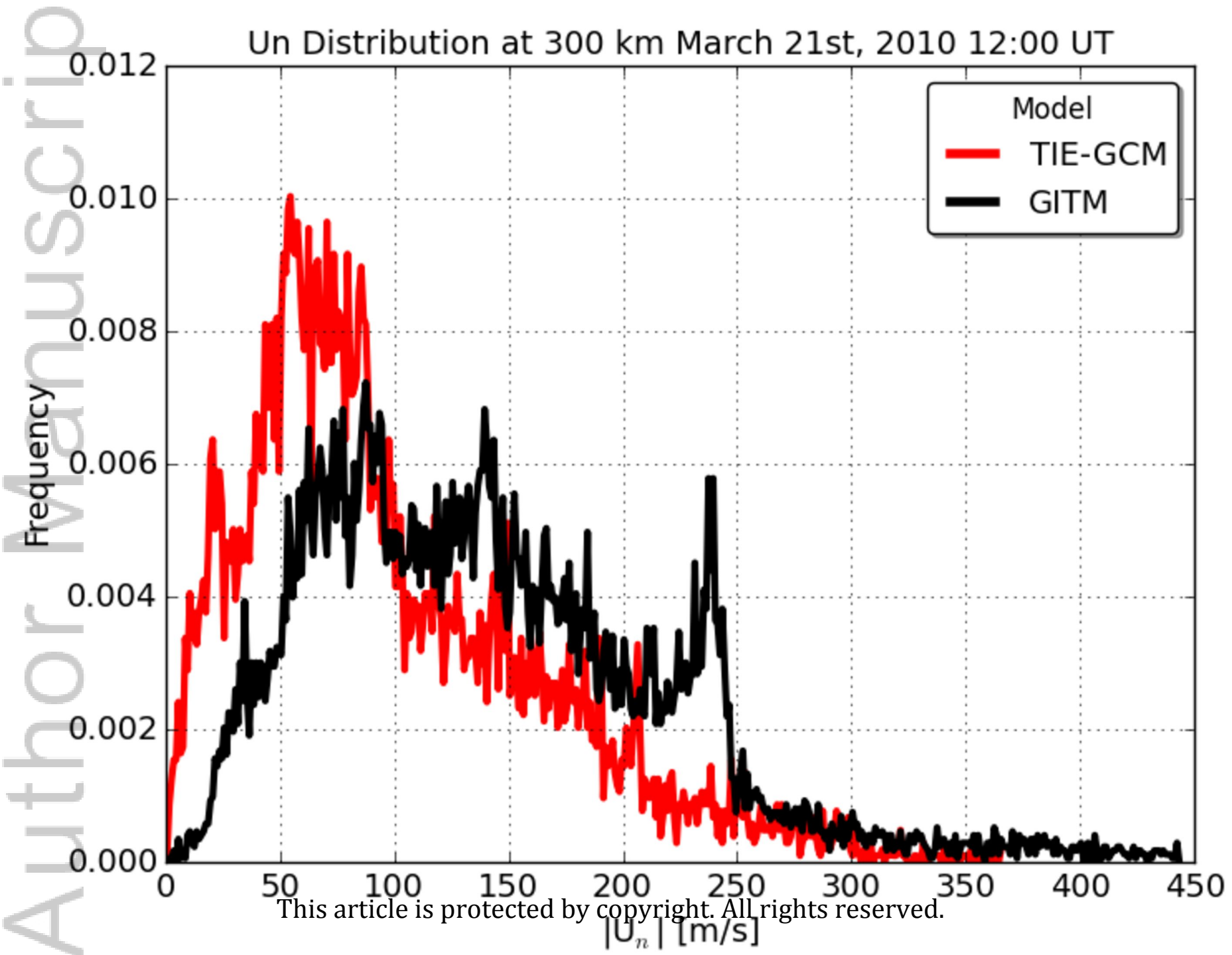

